\title{
Mineral-based composition with deliquescent salt as flame retardant for melamine-urea-formaldehyde (MUF)-bonded wood composites
}

Tomasz Ozyhar ${ }^{1)}{ }^{*}$, Christof Tschannen ${ }^{2)}$, Florentine Hilty ${ }^{1)}$, Heiko Thoemen ${ }^{2)}$, Joachim Schoelkopf ${ }^{1)}$, Justin Zoppe ${ }^{1)}$

1) Omya International AG, Baslerstrasse 42,4665 Oftringen, Switzerland

2) Bern University of Applied Sciences BFH, Solothurnstrasse 102, 2500 Biel, Switzerland

* corresponding author

$+41627892409$

tomasz.ozyhar@omya.com

\section{Abstract}

A flame retardant composition (FRC) composed of a surface-treated calcium carbonate-based mineral, having high porosity and loaded with deliquescent calcium chloride, was assessed for its potential as a flame retardant. Two FRCs with $16 \%$ and $26 \%$ calcium chloride (dry solid) stored in the pore structure, respectively, were studied with respect to their ability to absorb and release free water and their efficacy in melamine-urea-formaldehyde (MUF)bonded wood composites was investigated. Water absorption capacity was determined by performing absorption tests at a temperature of $20^{\circ} \mathrm{C}$ and relative humidity (RH) of $65 \%$ and $95 \%$ and the water release behaviour was studied by performing thermogravimetric analysis. The FRCs have the capacity to hold substantial amounts of water (up to $60 \mathrm{wt}$. \%), however still behave as a free-flowing powder. The influence of addition of 10 and $20 \mathrm{wt}$. $\%$ FRC in wood composites on reaction to fire and strength properties was determined by measuring the selfextinguishing time after flame exposure and internal bond strength, respectively. These effects were evaluated by comparing to ground calcium carbonate (GCC) and commercially available nitrogen containing phosphorus based fire retardant. Although the FRCs had a negative impact on internal bond strength, the results confirmed their flame retardant potential and showed that $10-15 \%$ by weight of the flame retardant would be a good compromise, in terms of the trade-off between flame retardancy and mechanical properties. The synergistic effects of multiple flame retardancy reaction mechanisms due to the presence of inorganic minerals and a hygroscopic agent, $\mathrm{CaCl}_{2}$, are also discussed. The unique properties of the FRC, which allow to exploit the fire retardant potential of $\mathrm{CaCl}_{2}$ while at the same time eliminating the risk associated with the emission of hydrogen chloride gas during combustion, is confirmed by the results of FTIR spectroscopic analyses of the flue gas. 
Keywords: calcium carbonate, calcium chloride, composites, engineered wood, flame retardant, melamine-urea-formaldehyde

\section{Introduction}

Structure fires, those involving residential or commercial buildings, can be devastating. In 2017, the International Association of Fire and Rescue Services (CTIF) reported nearly 850,000 structure fires among 23 of its member countries and 13,713 fire-related deaths (Brushlinsky et al. 2019). While fire prevention through education initiatives to increase public awareness is a lucrative strategy in reducing the number of structure fires and related deaths, the application of flame retardants (FRs) in structural building materials provides an effective means to reduce fire intensity and/or slow its spread in the event of a fire. As time is of the essence in such firerelated emergencies, FRs can have a great impact on the ability of emergency services to rescue humans or animals and minimize property damage. Improving the flame retardancy of woodbased composites is especially necessary, as it remains highly challenging to meet the ever evolving fire safety standards while, at the same time, reducing the impact on the environment and human health with current solutions (van der Veen and de Boer 2012). Numerous flame retardants, predominantly nitrogen and phosphorus containing compounds, have been suggested as effective solutions for application in wood and wood-based products (Lowden and Hull 2012, Mantanis et al. 2019). In addition, halogenated FRs, including boron-based compounds, such as boric acid (Pedieu et al. 2012; Wang et al. 2004), borax (Nagieb et al. 2010) or magnesium chloride (Khelfa et al. 2013) are known to increase the flame retardancy of wood composites.

While many of the FR solutions have been demonstrated to be effective in terms of their performance, their application presents a number of disadvantages. Among them, the hygroscopic nature of the salts and the associated water absorption capacity limits their use in wood products due to increased leaching, and mold formation (Östman et al. 2001). The presence of acids, commonly used to initiate an acid-catalyzed reaction, which decreases the temperature at which wood begins to decompose, leads to an associated decrease in strength (LeVan and Winady 1990). In addition, the use of some compounds, especially brominated flame retardants, as well their combustion products, raises serious environmental and health concerns (van der Veen and de Boer 2012). 
The application of naturally-occurring minerals is an alternative approach to state-of-the-art flame retardants with considerable potential in the field of wood-based products. The minerals discussed in the context of flame retardancy of wood include, e.g., hydroxyapatite (Khalili 2019), nano-wollastonite (Taghiyari 2013) or calcium carbonate (Merk et al. 2015). Moreover, a special group of FRs include inorganic metal hydroxides, such as aluminium hydroxide or magnesium hydroxide (Wu et el. 2014 , Khalili et al. 2017). In addition to reducing the overall flammable content in a composite material, their reaction mechanisms are based on the endothermic decomposition of the hydrate (heat absorption), which cools the wood and increases the time to ignition (Lowden and Hull 2012). Furthermore, the water vapour or carbon dioxide released by such hydrated minerals reduces the local concentration gaseous reactants, i.e. oxygen, in the flame.

There are numerous approaches to utilize minerals in wood-based composites with the goal of increasing their resistance to fire. The bottom-up approach includes the use of the minerals in the composite by combining the individual components and material processing to obtain a product with improved properties The inorganic constituents can be either incorporated and distributed homogenously throughout the matrix of the composite, as often applied for wood plastic composites (WPC) (Terzi et al. 2018), or applied as a protective layer, e.g. as a mineralbased coating (Özdemir and Tutuş 2016). In contrast, the top-down approach aims towards the modification and utilization of the hierarchical wood structure. An example of the top-down approach includes the precipitation of minerals from solution into the wood pore structure (mineralization), and has been demonstrated recently as an effective method to increase the fire resistance of wood using calcium carbonate, calcium oxalate or struvite (Merk et al. 2016; Franke and Volkmar 2019; Guo et al. 2019). While the latter approach is advantageous for application in solid timber (lumber), its economic viability remains highly questionable. Furthermore, considering the structure of the engineered wood products, the bottom-up approach seems to be more appropriate from the technological point of view. It is particularly advantageous for fiber- and particle-based products, in which inorganic constituents can be easily mixed with the wood constituents and processed into the final products, as demonstrated in Ozyhar et. al 2020 and Ozyhar 2020.

Using a bottom-up approach, this study investigates the use of a new type of flame retardant composition (FRC), based on mineral carrier with high porosity, which has been loaded with an inorganic salt (active substance). The FRC is intended to absorb and store a substantial 
amount of free water within the porous structure and it is expected to act as flame retardant by volatilization and release of the water vapour in the event of fire. This approach is unique, since it allows the use of a hygroscopic substance and storage of free water without the need for impregnation of the fiber. The technology is based on the assumption that water can be stored locally in the porous structure of the carrier. Potential negative effects associated with fiber impregnation, in particular the increased moisture content of the fiber and corresponding decrease in strength properties, can therefore be minimized.

To validate this hypothesis, this study is divided into three parts: I) the characterization of the physical properties of two different types of FRC, II) the self-extinguishing behaviour and mechanical properties of model wood panels based on single-layer particle board incorporating various amounts of the two different types of FRC and III) the combustion behaviour of industrially relevant three-layer particle board incorporating the most promising FRC candidate determined in part II. In more detail, the experiments performed in this study were first aimed at determining the water absorption capacity of the FRC, in order to assess its potential as a flame retardant (part I). In particular, the aim was to investigate the interplay between the amount of active substance within the porous structure of the mineral carrier and the total holding capacity of absorbed water. Furthermore, this investigation sought to elucidate the temperature-triggered water release mechanism from the FRC. The efficacy of the two different FRCs, reflected by their effect on the self-extinguishing potential and the influence on the strength properties was investigated to evaluate the potential for application in wood-based composites, in general (part II). Finally, the combustion behavior, including the analysis of the flue gases, was determined by performing cone calorimetry on a three-layer particle board containing the most promising FRC candidate to demonstrate its applicability in an industrially relevant product and to understand the fire retardant reaction mechanism governed by the FRC (part III).

\section{Material and methods}

\section{Materials}

\section{Mineral based carrier (C)}

Two different mineral based carrier materials (C1 and $\mathrm{C} 2$, respectively), provided by Omya International AG, were used in this study as components for manufacturing of the flame retardant composition (FRC). The carriers consist of about $41 \mathrm{wt}$ \% calcium carbonate $\left(\mathrm{CaCO}_{3}\right)$ 
and 59 wt. $\%$ of hydroxyapatite (HA) $\mathrm{Ca}_{5}\left(\mathrm{PO}_{4}\right)_{3}(\mathrm{OH})$ for $\mathrm{C} 1$ and 72 wt. $\% \mathrm{CaCO}_{3}$ and 24 wt. $\% \mathrm{HA}$ for $\mathrm{C} 2$. The individual mineral particles are present in the form of $\mathrm{CaCO}_{3}$ and lamellar structured HA on the surface of the particle (Fig. 1a,b). A weight median particle size $\left(\mathrm{d}_{50}\right)$ of $6.6 \mu \mathrm{m}$ and $2.4 \mu \mathrm{m}$, a specific surface area of $53 \mathrm{~m}^{2} / \mathrm{g}$ and $27 \mathrm{~m}^{2} / \mathrm{g}$, and an intraparticle intruded pore volume, as measured by mercury intrusion porosimetry (MIP), of $0.78 \mathrm{~cm}^{3} / \mathrm{g}$ and 0.50 $\mathrm{cm}^{3} / \mathrm{g}$ was measured for $\mathrm{C} 1$ and $\mathrm{C} 2$, each respectively (Fig. 2).

\section{Inorganic salt (active substance)}

An aqueous calcium chloride solution with $42 \%$ s.c. (solid content) was prepared from $\mathrm{CaCl}_{2}$ ( $\geq 93 \%$, anhydrous, granular, Merck, Kenilworth, NJ, USA) and served as an active substance (hygroscopic agent) in this study.

\section{Ground calcium carbonate (GCC)}

A ground calcium carbonate (GCC) with a $\mathrm{d}_{50}=30 \mu \mathrm{m}$ was used in the production of the singlelayer particle-board and served as an inert inorganic mineral used to investigate whether the replacement of combustible material (organic fibers) by inorganic material has any beneficial effect on the fire retardant properties.

\section{Benchmark flame retardant (FR)}

A nitrogen-containing phosphorus flame retardant composition (NP FRC) sold under the commercial name Ecochem MD 915-040 was obtained from EcoChem International NV, Belgium, and served as a benchmark flame retardant in this study.

\section{Wood material}

Wood particles for composite manufacturing originated from spruce (Picea abies (L.) Karst.) and were provided by Rauch Spanplattenwerk GmbH, Germany. The quality of the particles complied with the commercial grade utilized in particle board production (surface layer). The moisture content of the particles was $3 \%$ and the packing density was ca. $250 \mathrm{~kg} \mathrm{~m}^{-}{ }^{3}$.

\section{Resin}

Melamine-Urea-Formaldehyde (MUF) sold under the trade name Kauramin 620 was obtained from BASF SE. A solution of ammonium sulphate (Sigma Aldrich, purity $\geq 99 \%$ ) with a concentration of $40 \mathrm{wt}$. \% was used as catalyst (hardener) to accelerate the curing reaction of the resin. 


\section{Experimental}

\section{Manufacturing of FRCs}

Two flame retardant compositions, FRC1 and FRC2 were prepared by incipient wetness impregnation of $\mathrm{C} 1$ and $\mathrm{C} 2$, respectively, following the procedure described by Lundin et al. 2017. Both carriers were dried overnight at $150^{\circ} \mathrm{C}$ in an oven. The dry material was then agitated by a ploughshare mixer (Gebrüder Lödige Maschinenbau GmbH, Paderborn, Germany) and the aqueous $\mathrm{CaCl}_{2}$ solution was added dropwise to the respective carrier. The solution was absorbed by the inherent capillarity of the porous particles (Fig. 1c,d). The resulting products (FRC1 and FRC2) were dried overnight at $120^{\circ} \mathrm{C}$ to achieve a final $\mathrm{MC}$ under $3 \%$.

\section{Manufacturing of MUF wood composites}

\section{Single-layer particleboard}

Single-layer particle boards with $10 \mathrm{wt}$ \% and $20 \mathrm{wt}$ \%, with respect to wood content, of FRC1 and FRC2, respectively, and 15 wt. \% MUF, based on the dry wood mass, were manufactured to examine the fire extinguishing potential of the two FRCs and the effect of loading quantity on the processability and strength properties of the composite (part I). To ensure the adhesion of the FRCs to the wood particles and prevent particle and FRC segregation, wood particles were mixed with the resin prior to FRC addition using a mixer (Lödige FM 300D, Gebrüder Lödige Maschinenbau GmbH, Paderborn, Germany). Ammonium sulfate at rate of 3 wt. \% (based on solid resin) was used as a hardener to accelerate the curing of resin. The composites were processed using a laboratory press (Höfer HLOP 210, Höfer Presstechnik GmbH, Taiskirchen, Austria) with a press temperature of $200^{\circ} \mathrm{C}$ and to a final thickness of $12 \mathrm{~mm}$ and a target density of $650 \mathrm{~kg} \cdot \mathrm{m}^{-3}$, utilizing a press time of $180 \mathrm{~s}$. In addition to the composites with the FRC1 and FRC2, composites with $10 \mathrm{wt} \%$ NP FRC (flame retardant benchmark) and 10 wt. $\%$ and 20 wt. \% GCC addition (inactive mineral additive) were manufactured following the manufacturing procedure described above.

\section{Three-layer particle board}

Three-layer particle board with 20 wt.\%, with respect to wood content, of FRC1 in the outer layer and (MUF resin in outer and inner layer) MUF, based on the dry wood mass, were 
manufactured to investigate the effect of FRC on combustive behavior in an industrial like product (part III).

The surface layer of the three-layer particle boards contained 15 wt.\% of MUF resin and the core layer contained 12 wt.\% of MUF resin, both based on the dry wood mass. The surface layer was made using a fine material (the same that was used for manufacturing of the single layer particle board for experiments in part II, whereas the core layer utilized a coarse material i.e. the core layer quality material. Ammonium sulphate as hardener at a rate of $3 \mathrm{wt} . \%$ (based on solid resin) was applied for both the surface- and the core layer. The core layer material was mixed again using a mixer (Lödige), and the surface layer particles were mixed in a mixer (Drais T-100, Draiswerke GmbH, Mannheim, Germany). The composites were pressed on the same laboratory press (Höfer) with a press temperature of $200{ }^{\circ} \mathrm{C}$ utilizing a press factor of 15 $\mathrm{s} / \mathrm{mm}$, resulting in a press time of $240 \mathrm{~s}$. The target density was $650 \mathrm{~kg} \mathrm{~m}^{-3}$ and $16 \mathrm{~mm}$ thickness. The ratio of surface to core layer was $50 / 50$ with a symmetric structure i.e. $4 \mathrm{~mm}$ surface layer $-8 \mathrm{~mm}$ core layer $-4 \mathrm{~mm}$ surface layer.

In addition to the three-layer particle board containing FRC1 and a reference board without addition of FRC, two separate variants with the individual components of the FRC were manufactured i.e. composites with addition of inorganic carrier material (C1) and active substance $\left(\mathrm{CaCl}_{2}\right)$. The amount of $\mathrm{C} 1$ and $\mathrm{CaCl}_{2}$ used as an additive in the composite was normalized to the amount equal to the addition of the $20 \mathrm{wt} . \%$ FRC1. The amounts added were 14.7 wt. $\%$ for $\mathrm{C} 1$ and 5.1 wt. $\%$ for $\mathrm{CaCl}_{2}$, based on dry fibers. The boards with addition of $\mathrm{C} 1$ were manufactured following the procedure described above for the FRC. Calcium chloride was added as aqueous solution with 31.8 s.c. $\%$ on the fibers. The wood particles were dried afterwards to a final moisture content of $2.2 \%$ prior to mixing with resin following the procedure for a standard board without FRC addition.

Samples with dimensions $100 \mathrm{~mm} \cdot 100 \mathrm{~mm}$ were prepared for cone calorimetry testing. The back and edges of samples were sealed with aluminum foil with thickness of $0.02 \mathrm{~mm}$.

\section{Methods}

\section{SEM-EDX}

Scanning Electron Microscopy (SEM) combined with Energy-Dispersive X-Ray Analysis (EDX) were performed using Hitachi tabletop microscope TM3030 and $15 \mathrm{kV}$ voltage on the 
cross-section of the final composite samples. The sample preparation included a sputter coating with a thin gold layer of approximately $20 \mathrm{~nm}$.

\section{Water content and water absorption capacity}

The water absorption capacity for FRC1 and FRC2, as well the carrier (C) itself, was determined by acclimatizing the samples at a temperature of $20^{\circ} \mathrm{C}$ and relative humidity $(\mathrm{RH})$ of $65 \%$ and $95 \%$ for a period of 28 days in controlled climate chambers (Binder $\mathrm{GmbH}$, Tuttlingen, Germany). The samples were previously dried and the water content was determined at the beginning of the acclimatization period using a moisture analyzer (HB43-S, Mettler Toledo, Greifensee, Switzerland). The sample weight was measured at least every 7 days and the water content was calculated and expressed in wt.\% water based on the total weight of the FRC sample (including water).

In addition, water re-absorption capacity for FRC1 and FRC2, was determined by acclimatizing the samples at a temperature of $20^{\circ} \mathrm{C}$ and $65 \% \mathrm{RH}$ for 48 hours on samples previously exposed to a temperature of $200^{\circ} \mathrm{C}$ for a period of one hour. The water content of the FRCs was expressed as weight percent (wt.\%) of total weight of the FRC and was determined at $105{ }^{\circ} \mathrm{C}$ on the samples prior to composite processing using a halogen moisture analyzer (Mettler Toledo HE 73, Greifensee, Switzerland).

\section{Porosity measurements}

The pore size distribution of the carrier materials was determined using an Auto Pore V 9620 mercury porosimeter (Micromeritics Instrument, Norcross, GA, USA).

\section{Thermogravimetric analysis (TGA)}

Thermogravimetric analysis (TGA) was carried out on FRC1, FRC2 and the corresponding C1 and C2 carriers using a Mettler TC10A/TC15 analyzer (Mettler Toledo, Greifensee, Switzerland). Approximately $10-30 \mathrm{mg}$ of each test samples were analyzed at a heating rate of $10^{\circ} \mathrm{C} / \mathrm{min}$ in a temperature range of 30 to $800^{\circ} \mathrm{C}$ under air atmosphere with a flow rate of 20 $\mathrm{mL} / \mathrm{min}$.

\section{Measurement of temperature development in the wood composite}

The development of the temperature in the core and on the surface of the composite during composite processing (i.e. pressing in the hot press at $200^{\circ} \mathrm{C}$ ), was recorded using temperature 
sensors (thermocouple type $\mathrm{K}$ ) that were placed in the core and on the surface of the composite prior to processing. The temperature was plotted against the pressing time.

\section{Self-Extinguishing time measurements}

The efficacy of the FRCs was determined by measuring the self-extinguishing time of the composites in an adapted test setup following ISO 11925-2 (2010) using a burning chamber (KBK Taurus instruments GmbH, Weimar, Germany). Samples with dimensions of $200 \mathrm{~mm} x$ $14.5 \mathrm{~mm} \times 12 \mathrm{~mm}$ (thickness) were exposed to a flame for a period of $30 \mathrm{~s}$ at an angle of $45^{\circ}$ (Fig. 3). A total of 12 samples was tested per variant.

\section{Cone calorimetry}

The combustion properties were examined by carrying out cone calorimetry testing using Cone Calorimeter ISO/DIS 5660-1 apparatus by Dr.-Ing. Goerg Wazau Mess- + Prüfsysteme GmbH, Germany, coupled with a Fourier Transform Infrared Spectroscopy (FTIR) device. The measurements were performed on three-layered particle board samples utilizing a heat flux of $50 \mathrm{~kW} \cdot \mathrm{m}^{-2}$. Heat release rate (HRR) and total heat release rate (THR) were determined in following the ISO 5660-1 (2015). In addition, the flue gases were analysed by means of the FTIR spectroscopy.

\section{Determination of composite properties}

Internal bond strength (IB) and density of the composites were determined for samples acclimatized under standard climatic conditions $\left(20^{\circ} \mathrm{C}\right.$ and $\left.65 \% \mathrm{RH}\right)$ following the procedures described in SN EN 319:1993 using a universal testing machine (ZwickRoell Z030, ZwickRoell, Ulm, Germany). The moisture content of the composites was determined according to SN EN 322:1993. The IB and density was determined for 6 samples per variant and the moisture content for 10 samples per variant.

\section{Results and discussion}

The experiments conducted within the framework of this study were divided into parts I, II and III. The first part of this study focused on the characterization of FRC with respect to their use as FR in wood-based composites. The focus of the investigations performed in part I was on the measurement of the water absorption capacity and the water vapour release potential of the FRC. The main goal was to examine the relationship between the intrinsic porosity of the mineral carrier material and water absorption capacity of the FRC. Two different FRCs, 
manufactured using carrier materials characterized by different intrinsic porosity, were studied for their ability to store free water in the porous structure of the FRC as a function of relative humidity. The effectiveness of the FRC as potential FR was later evaluated by examining the temperature driven vaporization of water.

In part II of this study, the two FRCs characterized in part I, were examined for their potential application in wood panels. In a first feasibility study, both FRCs were compared in terms of their influence on processing parameters and their effect on the composites material properties. The influence on the temperature development during composite processing and the effect on the strength parameters was investigated on a model single-layer particle board manufactured with $10 \mathrm{wt} . \%$ and $20 \mathrm{wt} . \%$ addition in the panel, using both FRCs, respectively. In addition, a first evaluation of the effectiveness with regard to the fire retardant properties was carried out by comparing the self-extinguishing behaviour of the particle boards. The effectiveness of the FRCs was compared to the effect of a benchmark FR and addition of an inert inorganic mineral at equal addition quantities.

Based on the findings of part II, part III focused on the investigation of the fire retardant potential of FRC for application in an industrially relevant product. To that end, the combustion behavior of a three-layer particle board with $20 \mathrm{wt} . \%$ FRC1 addition in the outer layers was determined. The experiments carried out involved cone calorimetry testing and included the analysis of combustion gases, aimed at understanding the fire retardant reaction mechanism governed by the FRC. The characterization of the reaction mechanism of the FRC was complemented by investigating the contribution of the individual components of the FRC on the fire retardant mechanism i.e. carrier material (inorganic mineral) and active (hygroscopic salt).

\section{Part I: Characterization of FRC}

\section{Water absorption capacity}

The primary objective of this study was to utilize a porous mineral, which serves as a carrier of an active substance that can absorb and store water to be released in the event of flame ignition of a wood composite material. The capability of surface-modified calcium carbonate to absorb various classes of substances in the porous structure has been demonstrated by Lundin et. al 2017. The loading of an active substance is typically performed in a liquid state, either as a 
solution in an adequate solvent or as a melt. The interconnected pore network of the carrier is able to imbibe both polar and apolar liquids by the inherent capillary action (Ridgway et al. 2004, Ridgway et al. 2006). The interconnectivity ensures an even distribution of the fluid in the network driven by the Laplace pressures of the liquid menisci in the pores.

The expected flame retardant effect depends on the ability of the carrier to release the absorbed water in the event of fire, i.e. the temperature dependent vaporization of water. Unlike natural minerals, such as aluminium- or magnesium hydroxide, in which the water is bound to the crystal lattice, the flame retardant potential of the modified $\mathrm{CaCO}_{3}$ carrier depends on the ability of its porous structure to absorb and store water molecules. Our hypothesis stipulates that a higher water absorption capacity results in a higher flame suppressant potential.

The primary difference between carriers $\mathrm{C} 1$ and $\mathrm{C} 2$ is the composition of $\mathrm{CaCO}_{3}$ and $\mathrm{HA}$, which in turn has an impact on particle size, pore volume and specific surface area. Based solely on a specific surface area of $53 \mathrm{~m}^{2} / \mathrm{g}$ for $\mathrm{C} 1$ versus $27 \mathrm{~m}^{2} / \mathrm{g}$ for $\mathrm{C} 2$, we expected $\mathrm{C} 1$ to have higher water absorption capacity, whether loaded or unloaded with active substance. With an intrinsic water absorption capacity of less than $5 \mathrm{wt} . \%$ for $\mathrm{C} 1$ and $\mathrm{C} 2$ at $65 \% \mathrm{RH}$, the absorption capacity of the carriers themselves is relatively small, albeit higher in the case of C1 (Fig. 4a). Therefore, considering the amount of water stored in the carriers themselves, no major flame retardant effect can be expected. However, the absorption capacity of the carrier materials was increased dramatically when loaded with an hygroscopic agent, i.e. $\mathrm{CaCl}_{2}$ (Fig. 4b). With respect to $\mathrm{RH}$ between $65-95 \%$ investigated here, calcium chloride alone had a water absorption capacity between 65 wt. $\%$ and $80 \mathrm{wt}$ \%. In turn, the results demonstrated that the water uptake of the FRCs obtained using calcium chloride was increased by more than $20 \mathrm{wt} . \%$ and increased further up to $60 \mathrm{wt}$ \%, depending on the carrier composition and the RH. Here, it is worthwhile to note that despite the large amount of water stored in the porous structure, the FRCs remain free flowing powders.

The results further exemplified that the amount of water absorbed in the FRCs depends on RH (Fig. 4). As expected, the water content for the carriers and FRCs acclimatized at 95\% RH was notably higher than that of carriers and FRCs acclimatized at $65 \% \mathrm{RH}$. Conversely, lowering the RH below $65 \%$ would further decrease the water absorption capacity and potentially reduce the efficacy of the FRCs as a flame retardant. As the average RH in Central Europe, for example, usually falls between $65 \%$ and $95 \%$, $\mathrm{RH}$ outside of this range was not investigated. 
In addition to RH, the maximum water holding capacity of the FRCs is also, in part, determined by the available pore volume of the carrier. A higher pore volume allowed for a greater loading degree with $\mathrm{CaCl}_{2}$ and ultimately resulted in a higher water content in the final FRC (Table 1). The notably higher water content of the FRC1 compared to FRC2 can be explained by its higher intraparticle pore volume and the level of active salt that could be absorbed in the porous structure of the carrier (Fig. 4b). The calculated FRC1/FRC2 ratio in terms of water content equals to roughly 1.5 at $65 \% \mathrm{RH}$.

\section{Temperature driven vaporization of water}

Besides the water absorption capacity, the ability to release the water from the FRC composition in the event of fire, plays a decisive role when it comes to its efficacy as a flame retardant. A rapid release of the water at temperatures below the ignition temperature of wood is assumed to be advantageous with regard to the effectiveness of the FRCs. The results demonstrated that most water stored in the FRC was indeed released within a temperature range $100-200{ }^{\circ} \mathrm{C}$ (Fig. 5), which is lower than the ignition temperature of wood, reported around $250{ }^{\circ} \mathrm{C}$ with a directflaming ignition around $300-365{ }^{\circ} \mathrm{C}$ (Babrauskas 2002). The release of water vapour was interpreted as a cooling effect, which effectively increased the heat capacity of the gas phase, contributing to flame retardation (Hull et al. 2011).

As the water content of FRCs was relatively high, e.g. up to $60 \mathrm{wt} . \%$, there was a significant loss of water below a temperature of $100^{\circ} \mathrm{C}$, starting at a temperature of $25^{\circ} \mathrm{C}$ (start of the TGA measurement) (Fig. 5a). This initial loss of water measured in the early phase of the experiment at low temperatures was attributed to the adjustment in the equilibrium humidity between the FRC samples and the dry compressed air used in the TGA instrument. The large specific surface area of the carrier, which maximises the evaporation interface in relation to the large water mass likely triggered a rapid equilibration with the dry TGA atmosphere. Overall, the FRCs are believed to be rather stable in temperature ranges below $100{ }^{\circ} \mathrm{C}$. Under stable equilibrium conditions, the majority of the water is expected to be released from the FRC at temperatures in the range of $100-200{ }^{\circ} \mathrm{C}$. In agreement with the results of the water absorption capacity trials, the results from TGA reveal the differences in properties of FRC1 and FRC2. FRC1 had a significantly higher water absorption capacity compared to FRC2, which is explained by the corresponding differences in porosity of $\mathrm{C} 1$ and $\mathrm{C} 2$, leading to different $\mathrm{CaCl}_{2}$ loadings. In 
addition, the FRCs remained stable to thermal decomposition until about $600{ }^{\circ} \mathrm{C}$, after which surface chemical reactions likely occurred, leading to thermal degradation (to be discussed in more detail later). In contrast to FRC1 and FRC2, the TGA curve of the nitrogen-containing phosphorus benchmark FR, NP FRC, demonstrated a relatively low water content and a nearly constant rate of decomposition between 150 and $800{ }^{\circ} \mathrm{C}$.

In terms of the efficacy of the FRCs, the ability to retain water in the porous structure of the carrier until the event of a fire is a crucial characteristic. The high temperatures often utilized during wood composite manufacturing could have a negative impact on the FRCs. A temperature of $200{ }^{\circ} \mathrm{C}$, which is prevalent during the manufacturing of such composites, could indeed have an effect on the final amount of available water in the FRCs to be later released in the event of a fire. The principle ability of the FRC to absorb the water once incorporated in the composite therefore plays a decisive role for the efficacy as an FR, in general.

In order to investigate the ability of FRCs to (re-)absorb water following high temperature processing, the water absorption capacity at $65 \% \mathrm{RH}$ was determined for samples previously exposed to a temperature $200{ }^{\circ} \mathrm{C}$ for 1 hour. Figure $6 \mathrm{a}$ and $6 \mathrm{~b}$ demonstrate that most of the water lost (Fig. 6a) was re-absorbed within a very short period of time, e.g. between 24-48 hours, indicating that the process is reversible. The behaviour is due to the nature of hygroscopic salts that must reach equilibrium with the surrounding humid environment. Therefore, even when water is lost, e.g. at elevated temperature in the production process of the wood composite, the hygroscopic compound would presumably re-absorb moisture in the composite from the surrounding ambient air, the rate of which would depend on the RH. The observed re-absorption was furthermore independent of the carrier, showing overall that the water lost can be regained within roughly 48 hours. For practical applications, this implies that a 48-hour equilibration period at $65 \% \mathrm{RH}$ after composite manufacturing may be sufficient for FRCs to reach their maximum amounts of absorbed moisture.

\section{Part II: Influence of FRC addition on the processability and material properties of single-layer particleboard}

With regard to the efficacy of the FRCs in wood composites, a homogenous distribution is considered a prerequisite for effective performance in the event of a fire. The feasibility of incorporating mineral additives in urea-formaldehyde-bonded wood composites was recently 
demonstrated in Ozyhar et. al 2020 and Ozyhar 2020. A key element in achieving homogenous distribution and preventing component separation associated with different packing densities of fibers and minerals, is the addition sequence of the components. By applying the resin on the fiber prior to addition of minerals, the adhesion of the mineral to the fiber can be ensured. Using this approach, homogenous distribution of the FRCs in the fiber furnish was also realized in the current investigation (Fig. 7). The small deviation in the final density of the composite further supports that a good distribution of the additive was achieved and that separation did not have a considerable effect on the composite properties (Table 2). As the FRCs remain free-flowing powders, even with a substantial amount of absorbed water (shown in part I), it is assumed that, once incorporated in the composite, they do not have a strong influence on the resin and the surrounding wood fibers during processing.

\section{Temperature development during manufacturing of wood composites}

With regard to the application of the FRCs in composites utilizing thermosetting resins, the effect on the temperature-dependent hardening reaction of the resin is of interest. In particular the influence on the temperature development during the thermal processing plays a crucial role in relation to strength development. The temperature dependency of the curing reaction on strength development of composites containing thermosetting resins is well-known (Gul et al. 2017). Changes in the temperature profile caused by addition of FRC might have negative effects on the curing dynamic of the resin and weaken the strength bond formation by incomplete curing.

FRC addition did not have a notable effect on the temperature development on the surface of the composite (Fig. 8). However, FRC addition did have an impact on the temperature development in the core of the composite. The maximum temperature of the composites containing FRCs that was reached, after the preheating phase $(0-80 \mathrm{~s})$, was about $10{ }^{\circ} \mathrm{C}$ degrees above the temperature of the reference.

The increase in temperature is hypothesized to be attributed to differences in the specific heat capacity, in which wood has a value twice that of the mineral component of the carrier material. This was likewise suggested by Ozyhar et al. 2020, who demonstrated that addition of calcium carbonate to MDF increases the temperature in the core of the composite during processing. 
Based on the evidence above, the influence of the manufacturing process on the final composites properties was therefore deemed insignificant.

\section{Internal bond strength}

One disadvantage of flame retardants in wood-based composites is that they usually require the addition of substantial amounts, which negatively affects other material properties (Khalili et al. 2017). The performance of novel fire retardant solutions should therefore always be considered in light of their impact on other material properties, such as internal bond (IB) strength.

In this study, the addition of GCC at $10 \mathrm{wt}$ \% did not notably change the internal bond strength (Fig. 9), in agreement with previous work (Ozyhar et. al 2020 and Ozyhar 2020). In contrast, the addition of FRCs had a more pronounced effect on internal bond strength compared to standard GCC, which was comparable to the effect of the benchmark NP FRC at the same rate of addition. One potential explanation for these observations is the high surface area of the carrier material of the FRCs compared to the GCC. As a result of high surface area, the resin might have been absorbed by the pores of the FRCs and was, thus, no longer available for bond formation between the wood particles. However, the decline in IB strength by roughly $30 \%$, as demonstrated for the FRC1 and FRC2 at 10 wt. \% addition, can be potentially justified by a positive effect on flame retardancy (see below). From a practical standpoint, such a strength decrease could, nonetheless, be compensated by increasing the amount of resin in the formulation.

\section{Self-extinguishing properties}

The efficacy of the FRC is best illustrated by the self-extinguishing time recorded for composites, with and without FRC addition, exposed previously to fire (Fig. 10). Of the tested variants, no time could be recorded for composites with the NP FRC benchmark, FRC1 at 10 wt. $\%$ and FRC1 and FRC2 at 20 wt. \% addition, respectively. The immediate extinction of the flame for these samples indicated a very high self-extinguishing potential. Moreover, the results demonstrated that the efficacy of FRC1 was comparable to that of the benchmark NP FRC at 10 wt. $\%$ addition rate in the composite. Finally, these results indicated that an additional increase of the FRCs beyond $10 \mathrm{wt} \%$ in the composite formulation did not have a notable 
effect on the flame retardant properties under the conditions tested. GCC (inactive calcium carbonate mineral) did neither show a significant improvement of the fire exstinguising properties up to an addition rate of $20 \mathrm{wt}$. \%. The flame duration measured for both composites with 10 and 20 wt. \% GCC addition was more than 3 seconds, which is considered the limit for passing the self-exstinguising time. This indicated that the effect of the FRCs cannot be solely attributed to replacement of combustible material with an inorganic additive.

\section{Part III: Fire retardant properties of three-layer particle board containing FRC1}

\section{Combustion behavior}

Building on the promising results for the self-extinguishing trials obtained for the single-layer particle board as discussed above in part II, industrially relevant three-layer particle board containing $20 \mathrm{wt} . \%$ of FRC1 were manufactured and cone calorimetry was performed to verify FRC1 performance. The aim of this part of the investigation was to examine the combustion behavior and to characterize the reaction mechanism governed by the FRC. The effect of FRC1 addition on the reaction to fire was further compared to the individual components of the FRC i.e. the mineral carrier $(\mathrm{C} 1)$ and the active substance $\left(\mathrm{CaCl}_{2}\right)$, within three-layer particle board.

The results clearly showed that the addition of FRC1 to the outer layer of the composite has a positive effect on the reaction to fire, demonstrated by the reduced heat release and markedly lower peaks for the heat release rate (HRR) and the total heat release rate (THR) curve, when compared to the reference (Fig. 11a,b). In particular, the HRR during the first $200 \mathrm{~s}$ of the experiment (first shoulder of the HRR curve in Fig. 11a), demonstrated the effect of the FRC. Here it is noteworthy that the effect of the FRC outperformed the effect of the $\mathrm{CaCl}_{2}$ alone, which is shown by the absolute values of the THR (Fig. 11b). The quantitative evaluation revealed that the impact of the FRC at an addition rate of $20 \mathrm{wt} \%$ was accompanied by a reduction of heat release of roughly $25 \%$ and $33 \%$ for the $\mathbf{Q}_{\mathbf{A}}$, tot (heat release per unit area) and $\mathbf{q}^{\circ} \mathbf{A}, \max$, (total heat per unit area released during the entire test), respectively (Tab. 3).

While the fire retardant mechanism for the FRC can be partly explained by the vaporization of water and the associated endothermic reaction, the comparison of the behavior for panels with FRC1 and panels containing $\mathrm{CaCl}_{2}$ provided evidence that the fire retardant reaction mechanism cannot be explained by the vaporisation of water alone. Considering the fact that the amount of $\mathrm{CaCl}_{2}$ for the panels manufactured using $\mathrm{FRC} 1$ and the $\mathrm{CaCl}_{2}$ was equal, the amount of water absorbed and released from the two panels was assumed to be similar. Clearly, another 
mechanism contributed to the reduction in heat released during the combustion. Taking into account the effect of the carrier itself on the HRR during combustion, the results point to a synergistic effect from the application of the two components in combination, i.e. FRC1. It is noteworthy that the THR over the entire duration of the fire test was lower than that obtained for the individual components.

In addition to the effect on the heat release, the FRC had a considerable effect on the smoke production. Compared to the reference, the addition of the FRC reduced the smoke production by almost half, as demonstrated by the total smoke production (TSP) (Fig. 11d). The influence was particularly evident during the first $200 \mathrm{~s}$ of the fire test and in the smoke production rate (SPR) (Fig 11c). It can be seen that not only the FRC, but also the $\mathrm{CaCl}_{2}$ when applied alone, significantly reduces smoke production.

Next to smoke release, the release of potentially toxic gases is an important issue to be considered when assessing the potential of new flame retardant compositions. While the application of $\mathrm{CaCl}_{2}$ has been mentioned as an effective flame retardant e.g. by Cheng et al. 2019, its application is increasingly restricted due to a growing global concern about the possible health impacts. The primary concern with the application of $\mathrm{CaCl}_{2}$ is related to the release of hydrogen chloride during combustion, known as an incapacitating irritant (Hull et al. 2009).

The analysis of the smoke by means of FTIR spectroscopy revealed the release of hydrogen chloride gas during combustion for the panels containing free $\mathrm{CaCl}_{2}$, demonstrating its hazard potential. On the contrary, the $\mathrm{HCl}$ gas emissions for FRC1 were practically negligible, even though the effective amount of $\mathrm{CaCl}_{2}$ in the panel was equal in both cases (Fig. 12). This indicated that the $\mathrm{HCl}$ emissions were completely absorbed by FRC1 within the panel. This behavior can be explained by the adsorbent $\mathrm{CaCO}_{3}$ component of the carrier material of FRC1. The use of application of $\mathrm{CaCO}_{3}$ as an effective agent to neutralise $\mathrm{HCl}$ emissions, e.g. during PVC combustion, is well known (Matthews and Plemper 1981; Tian et al. 2003).

These results highlight the unique feature of the FRC, in which it is able to minimize the risk associated with the release of hydrogen chloride gas during combustion through adsorption. The advantage of FRC over the use of free $\mathrm{CaCl}_{2}$ is that it allows the exploitation of the fire retardant potential of halides while minimizing the risk associated with their chemical hazards. 
While the absolute influence of the FRC addition on heat release amounts to roughly $30 \%$, the effect of the FRC must be evaluated taking into account the self-extinguishing potential of the FR. This was demonstrated by the self-extinguishing times determined in part II (Fig. 10) and further confirmed with the cone experiment (Table 3).

\section{Potential flame retardancy mechanisms of mineral-based FRCs}

Thus far, the main flame retardant mechanism originally proposed is ascribed to the cooling effect associated with the release of water and the potential of the FRCs to lower the temperature below the ignition temperature of wood. The water vapour liberated further has a dilution effect on the gas phase and forms an oxygen-displacing protective layer (Lowden and Hull 2012).

While the self-extinguishing potential achieved at $10 \mathrm{wt}$ \% based on the composites total weight appears promising, especially compared to other mineral fillers (Hull et al. 2011), it suggests that in addition to the release of water from the pores, other flame retardant mechanisms must contribute to the overall efficacy of the FRCs. It should be mentioned here that, considering an average water content of $30 \mathrm{wt} . \%$ in the FRCs, the overall composite water content, at an addition rate of $10 \mathrm{wt}$ \% FRC, amounts to $3 \mathrm{wt}$. \%. In fact, the measured increase in moisture content of the composites as a result of FRC addition were below the expected values based on the measured moisture content of the individual components (Table 2). The determination of moisture content of the wood composites at $103 \pm 2{ }^{\circ} \mathrm{C}$, as defined by the standard, could have underestimated the actual water content when compared to the results from the moisture analyzers (Table 1), which have higher sensitivity. Nevertheless, the incorporation of the high porosity FRC1 in the compositions resulted in a substantial increase in overall moisture content.

In addition to temperature-triggered release of water, the hydration/dehydration behaviour of $\mathrm{CaCl}_{2}$ itself might have played a role in the flame retardancy. This compound goes through six different stages of hydration from $\mathrm{CaCl}_{2}$ to $\mathrm{CaCl}_{2} \times \mathrm{H}_{2} \mathrm{O}$ to $\mathrm{CaCl}_{2} \times 2 \mathrm{H}_{2} \mathrm{O}$ to $\mathrm{CaCl}_{2} \times 4 \mathrm{H}_{2} \mathrm{O}$ to $\mathrm{CaCl}_{2} \times 6 \mathrm{H}_{2} \mathrm{O}$ to dissociated $\mathrm{Ca}^{2+}$ and $2 \mathrm{Cl}^{-}$, each of which exhibiting different thermodynamic properties. Even in a dissociated state, the boiling point rises up to $122{ }^{\circ} \mathrm{C}$ at a concentration of 42 wt. $\%$ in solution. The hydrates are known to boil at $174{ }^{\circ} \mathrm{C}, 183{ }^{\circ} \mathrm{C}$ and $1935{ }^{\circ} \mathrm{C}$ going from the dihydrate to the hydrate to the anhydride form, respectively. The rise of the boiling point and the associated increase in vaporization enthalpy contribute to energy dissipation from the burning process and, therefore, a prolonged release of vapour. Thus, the hydration state of $\mathrm{CaCl}_{2}$ itself could have an impact on the flame retardancy of the FRCs, as it can exhibit a range of 
boiling points. Another aspect that should be mentioned for completeness, although probably negligible, is associated with the effect of carrier porosity on the boiling point of water. For example, Hiejima and Yao (2004) measured elevated boiling points of water, e.g. $115{ }^{\circ} \mathrm{C}$, confined in $7 \mu \mathrm{m}$ pores compared to bulk water, which might also contribute to a sustained vapour release.

Another flame retardancy mechanism that presumably contributed to the performance of the FRCs, is linked directly to the temperature-dependent decomposition of active component i.e. $\mathrm{CaCl}_{2}$ in the FRCs. The ability of the chlorinated FR to interfere with the free radical mechanism of the combustion process by preventing hydroxide and hydrogen free radicals from reacting with oxygen and carbon monoxide, is well known and explained by the free radical theory (Troitizsch 1998). The decomposition of the salt is expected to take place following the reaction:

$$
\begin{gathered}
\mathrm{CaCl}_{2} \cdot 6 \mathrm{H}_{2} \mathrm{O}(\mathrm{s}) \rightarrow \mathrm{Ca}(\mathrm{OH}) \mathrm{Cl}(\mathrm{s})+\mathrm{HCl}(\mathrm{g})+5 \mathrm{H}_{2} \mathrm{O}(\mathrm{g}) \\
\mathrm{Ca}(\mathrm{OH}) \mathrm{Cl}(\mathrm{s}) \rightarrow \mathrm{CaO}(\mathrm{s})+\mathrm{HCl}(\mathrm{g})
\end{gathered}
$$

The hydrogen chloride, created in the reaction from chlorine radicals and the hydrocarbon molecules in the flammable gas mixture (smoke) was believed to play an additional role in the efficacy of the FRCs. The hydrogen chloride gas was further expected to react with the $\mathrm{CaCO}_{3}$ component of the mineral carrier at temperatures above $600^{\circ} \mathrm{C}$ leading to release of carbon dioxide (Shemwell et al. 2001):

$$
\mathrm{CaCO}_{3}(\mathrm{~s})+2 \mathrm{HCl}(\mathrm{g})=>\mathrm{CaCl}_{2}(\mathrm{~s})+\mathrm{H}_{2} \mathrm{O}(\mathrm{g})+\mathrm{CO}_{2}(\mathrm{~g})
$$

The peak in the TGA with the temperature maxiumum around $680^{\circ} \mathrm{C}$ (Fig. 5b) corresponds well with the reaction temperature reported by Shemwell et al. 2001. Following the gas dilution, the $\mathrm{CO}_{2}$ would lead to a reduction in the combustible gas and contribute to self-extinguishing. Ultimately, it was likely the release of $\mathrm{CO}_{2}$ that contributed to self-extinguishing properties of the FRCs (Eq. 3). In this context, the release of $\mathrm{HCl}$ gas, considered a disadvantage for chlorinated flame retardants, is an essential part of the flame retardancy mechanism of the FRCs presented here. The FRC2 exhibited a higher weight loss than FRC1 at temperatures above 680 ${ }^{\circ} \mathrm{C}$, which was probably related to the higher $\mathrm{CaCO}_{3}$ content in the $\mathrm{FRC} 2$ composition and the proportionally higher amount of $\mathrm{CO}_{2}$ released as a result of the reaction with $\mathrm{HCl}$ (Eq. 3). 
While the flame retardancy effect from acid catalyzed oxygen-eliminating reactions of wood at a relatively low temperature is well known (Wang et al. 2004), the presence of acids has a negative influence on the strength properties of wood, due to its accelerated degradation (LeVan and Winady 1990). The advantage of the FRC compared to e.g. boric acid, is that the FRC does not contain free acid in its composition, but is generated in situ in the event of fire. Therefore, the negative impact of accelerated wood decomposition can be excluded. As demonstrated by FTIR spectroscopy performed for the flue gas (Fig. 12), the FRC1 has the unique ability to completely neutralize the $\mathrm{HCl}$ gas.

It must be stressed here that the amount of $\mathrm{CaCl}_{2}$ used in this study did not exceed 2.6 wt. \% based on the total weight of the composite (for $10 \mathrm{wt}$. \% FRC1 addtion). This amount is quite low when compared to $5 \mathrm{wt}$ \% calcium chloride, for instance, that was cited as effective in increasing charring during combustion in bamboo (Cheng et al. 2019). Moreover, magnesium chloride hexahydrate was shown to be an effective FR for cellulose fabric at addition rates exceeding 35 wt. \% (Esmail et al. 2001).

Self-extinguishing properties of the FRCs can be further attributed to the hydroxyapatite component present in the mineral carrier. Hydroxyapatite has been mentioned as an effective fire extinguisher and smoke supressant by Liu et al. 2015 and Guo et al. 2018. The selfextinguishing mechanism of nanohydroxyapatite addition is attributed to the formation of a stable protective char layer, shielding the underlying materials from the flame zone and heat. In addition to its functon as a protecitve layer preventing heat transfer, the char layer might also serve as a physical barrier reducing the transport of oxygen and other flammable gases. Finally, hydroxyapatite nanoplatelets were shown to release active flame scavengers, such as $\mathrm{PO}_{2}, \mathrm{PO}$ and HPO` (Elbasuney and Maraden 2019).

While none of the above mentioned flame retardancy mechanisms alone explains the performance of FRCs in the wood composite presented here, we propose such effects combined can form the basis for understanding the efficacy of the FRCs. In conclusion, it is hypothesized that the overall performance of the FRCs can be attributed to a synergistic effect of three different flame retardancy mechanisms: a) release of water vapour at temperatures in the range $100-200{ }^{\circ} \mathrm{C}$ contributing to heat absorption associated with the endothermic reaction as well as dilution of flammable gases, b) dilution of flammable gases by non-flammable decomposition 
products from hydroxyapatite and reaction of $\mathrm{CaCO}_{3}$ with $\mathrm{HCl}$ at temperatures above $600^{\circ} \mathrm{C}$ and c) char layer formation related to the decomposition of hydroxyapatite.

\section{Conclusions}

Herein, the efficacy of a flame retardant composition (FRC) composed of a mineral with high porosity (carrier) and an inorganic salt (active substance) stored in the porous structure of the carrier for application in MUF wood composites was presented. The experimental results demonstrated that the efficacy of the FRC depends both on the available pore volume of the mineral component and its ability to absorb and store water. A considerable amount of water can be absorbed and stored in the FRC (up to $60 \mathrm{wt}$. \% with respect to the FRC), while remaining as a free-flowing powder. The stored water can be potentially released in the event of a fire, acting as a flame retardant in addition to a synergistic effect of the inorganic mineral and active (hygroscopic substance) of the FRC. The feasibility for the FRCs application as a flame retardant in single-layer MUF wood composites was shown through self-extinguishing experiments and reaction to fire performed in cone calorimetry. FRC addition at $10 \mathrm{wt}$. \% was sufficient to achieve immediate self-extinguishing properties, albeit at the expense of a decrease in internal bond strength by roughly $30 \%$. Based on this outcome, it was concluded that the application of $10 \mathrm{wt}$ \% FRC would represent a good compromise, in terms of the trade-off between flame retardancy and mechanical properties.

The results of the combustion experiments and cone calorimetry carried out on industrially relevant three-layer particle board demonstrated that the fire reaction mechanism involved more than the mere release of water and can be explained by the synergetic effect of $\mathrm{CaCl}_{2}$ (active substance) and the inorganic carrier material. The analysis of the flue gases further revealed the unique feature of the FRC, which allows for utilizing the flame retardant potential of $\mathrm{CaCl}_{2}$, while eliminating the risk associated with the release of hazardous hydrogen chloride gas during combustion.

\section{Acknowledgments}

The authors would like to thank the team of the Institut für Holztechnologie Dresden gemeinnützige GmbH (IHD) for performing the cone calorimetry experiments.

\section{Funding}

This study was funded by Innosuisse (Swiss Innovation Agency) Project No. 34008.1 IP-EE. 


\section{Conflict of Interest}

The authors declare that they have no conflict of interest. 


\section{References}

Babrauskas V (2002) Ignition of Wood: A Review of the State of the Art, J Fire Prot Eng 12:163-189. doi:10.1177/10423910260620482

Brushlinsky N, Ahrens M, Sokolov S and Wagner P (2019) World Fire Statistics, International Association of Fire and Rescue Services (CTIF), Issue no 24 - 2019. https://www.ctif.org/sites/default/files/news_files/2019-04/CTIF_Report24_ERG.pdf

Cheng D, Li T, Smith G, Yang J, Hang C, Miao Z, et al. (2019) Influence of calcium chloride impregnation on the thermal and high-temperature carbonization properties of bamboo fiber, PLoS ONE 14(2): e0212886. doi.org/10.1371/journal.pone.0212886

Elbasuney S and Maraden A (2020) Novel Thermoset Nanocomposite Intumescent Coating Based on Hydroxyapatite Nanoplates for Fireproofing of Steel Structures, J Inorg Organomet P 30:820-830. doi.org/10.1007/s10904-019-01260-7

Esmail WA, Darwish AMY, Ibrahim, OA, Abadir MF (2001) The Effect of Magnesium Chloride Hydrate on the Flame retardation of Cellulosic Fibers, J Therm Anal Calorim 63:831-838. doi.org/10.1023/A:1010160625770

Franke T and Volkmer T (2019) Treatment of European beech with a new wood flame retardant agent based on in situ deposition of calcium oxalate, Holzforschung 73(11):1047-1050. doi.org/10.1515/hf-2019-0043

Guo W, Wang X, Zhang P, Liu J, Song L, Hu Y (2018) Nano-fibrillated cellulosehydroxyapatite based composite foams with excellent fire resistance, Carbohydr Polym 195:71-78. doi.org/10.1016/j.carbpol.2018.04.063

Guo H, Luković M, Mendoza M, Schlepütz C, Griffa M, Xu B, Gaan S, Herrmann H, Burgert I (2019) Bioinspired Struvite Mineralization for Fire-Resistant Wood, ACS Appl Mater Interfaces 11(5):5427-5434. doi.org/10.1021/acsami.8b19967

Gul W, Khan A, Shakoor A (2017) Impact of Hot Pressing Temperature on Medium Density Fiberboard (MDF) Performance, Adv Mater Sci Eng 1:1-6. doi: 10.1155/2017/4056360

Hamdani - Devarennes S, Longuet C, Sonnier R, Ganachaud F, Lopez-Cuesta JM (2013). Calcium and Aluminium-Based Fillers as Flame-Retardant Additives in Silicone Matrices. III. Investigations on Fire Reaction, Polym Degrad Stabil 98(10):2021-2032. doi.org/10.1016/j.polymdegradstab.2013.07.009

Hiejima Y and Yao M (2004) Phase behaviour of water confined in Vycor glass at high temperatures and pressures, J Phys-Condens Mat 16(45): 7903. doi:10.1088/0953$8984 / 16 / 45 / 012$ 
Hull R, Stec A, \& Paul K (2009). Hydrogen Chloride in Fires. Fire Safety Science. 9. 10.3801/IAFSS.FSS.9-665.

Hull R, Witkowski A, Hollingbery L (2011) Flame retardant action of mineral fillers, Polym Degrad Stabil 96(8):1462-1469. doi.org/10.1016/j.polymdegradstab.2011.05.006

International Organization for Standardization (ISO) (2010) 11925-2. Reaction to fire tests Ignitability of products subjected to direct impingement of flame - Part 2: Single-flame source test.

International Organization for Standardization (ISO) (2015) ISO 5660-1. Reaction-to-fire tests - Heat release, smoke production and mass loss rate — Part 1: Heat release rate (cone calorimeter method) and smoke production rate (dynamic measurement).

Khalili P, Tshai KY, Kong I, Hui D (2017) Synergistic of ammonium polyphosphate and alumina trihydrate as flame retardants for natural fiber reinforced epoxy composite, Compos B Eng 114(1):101-110. doi.org/10.1016/j.compositesb.2017.01.049

Khalili P, Liu X, Zhao Z, Blinzler B (2019) Fully Biodegradable Composites: Thermal, Flammability, Moisture Absorption and Mechanical Properties of Natural FibreReinforced Composites with Nano-Hydroxyapatite, Materials. 12(7):1145. doi.org/10.3390/ma12071145

Khelfa A, Bensakhria A, Weber JV (2013) Investigations into the pyrolytic behaviour of birch wood and its main components: Primary degradation mechanisms, additivity and metallic salt effects, J Anal Appl Pyrol 101:111-121. doi.org/10.1016/j.jaap.2013.02.004

LeVan SL, Winandy J (1990) Effects of flame retardant treatments on wood strength: a review, Wood Fiber Sci 22(1):113-131.

Liu XL, Hu ZW, Zhang S, Gu XY, Ma WJ (2015) Effect of hydroxyapatite on fire resistance and smoke suppression of polyurethane fire-retardant coating, Xiandai Huagong/Modern Chemical Industry 35(5):88-91.

Lowden LA, Hull TR (2013) Flammability behaviour of wood and a review of the methods for its reduction, Fire Sci Rev 2(4). doi.org/10.1186/2193-0414-2-4

Lundin M, Noreland D, Gane P, Schoelkopf J, Ridgway C, Millqvist-Fureby A (2017) Porous calcium carbonate as a carrier material to increase the dissolution rate of poorly soluble flavouring compounds, Food Funct 8:1627-1640. doi.org/10.1039/C6FO01579D

Mantanis G, Martinka J, \& Lykidis C, Ševčík L (2019) Technological properties and fire performance of medium density fibreboard (MDF) treated with selected polyphosphatebased flame retardants, Wood Mater Sci. doi.org/10.1080/17480272.2019.1596159 
Matthews G, Plemper GS (1981) Effects of calcium carbonate fillers on the behaviour of PVC in fires, British Polymer Journal 13(1):17-21.

Merk V, Chanana M, Keplinger T, Gaan S, Burgert I (2015) Hybrid wood materials with improved flame retardance by bio-inspired mineralisation on the nano- and submicron level, Green Chem 17(3):1423-1428. doi.org/10.1039/C4GC01862A

Merk V, Chanana M, Gaan S, Burgert I (2016) Mineralization of wood by calcium carbonate insertion for improved flame retardancy, Holzforschung 70(9):867-876. doi.org/10.1515/hf-2015-0228

Nagieb Z, Nassar M, El-Meligy M (2011) Effect of Addition of Boric Acid and Borax on FireRetardant and Mechanical Properties of Urea Formaldehyde Saw Dust Composites, Int J Carbohydr Chem. doi.org/10.1155/2011/146763

Ozyhar T, Depnering T, Ridgway C, Welker M, Schoelkopf J, Mayer I, Thoemen H (2020) Utilization of inorganic mineral filler material as partial replacement for wood fiber in medium density fiberboard (MDF) and its effect on material properties, Eur J Wood Wood Prod (78)1:75-84. doi.org/10.1007/s00107-019-01480-1

Ozyhar T (2020) Application of mineral filler in surface layer of three-layer particle board and its effect on material properties as a function of filler content, Int Wood Prod J.(11):3:109-114. doi:10.1080/20426445.2020.1735753

Östman B, Voss A, Hughes A, Hovde P, Grexa O (2001) Durability of flame retardant treated wood products at humid and exterior conditions. review of literature, Fire Mater 25(3):95-104. doi.org/10.1002/fam.758

Özdemir F, Tutuş A (2016) Effects of Coating with Calcite together with Various Fire Retardants on the Fire Properties of Particleboard. BioRes 11(3): 6407-6415.Pedieu R, Koubaa A, Riedl B, Wang XM, Deng J (2012) Fire-retardant properties of wood particleboards treated with boric acid, Eur J Wood Wood Prod 70:191-197. doi.org/10.1007/s00107-011-0538-y

Ridgway C, Gane P, Schoelkopf J (2004) Modified Calcium Carbonate Coatings with Rapid Absorption and Extensive Liquid Uptake Capacity, Colloid Surface A 236(1-3): 91-102. doi.org/10.1016/j.colsurfa.2003.12.030

Ridgway C, Gane P, Schoelkopf J (2006) Achieving Rapid Absorption and Extensive Liquid Uptake Capacity in Porous Structures by Decoupling Capillarity and Permeability: Nanoporous Modified Calcium Carbonate, Transport Porous Med 63:239-259. doi.org/10.1007/s11242-005-5391-1 
Shemwell B, Levendis Y, Simons G (2001) Laboratory study on the high-temperature capture of $\mathrm{HC} 1$ gas by dry-injection of calcium-based sorbents, Chemosphere 42(5-7):785-796. doi:10.1016/s0045-6535(00)00252-6

SN EN (1993) 319. Particleboards and fibreboards - Determination of tensile strength perpendicular to the plane of the board (In German).

SN EN (1993) 322. Wood-based panels - Determination of moisture content (In German).

Taghiyari HR, Rangavar H, Nouri P (2013) Fire-retarding properties of nanowollastonite in MDF, Eur J Wood Wood Prod 71(5):573-58. doi.org/10.1007/s00107-013-0711-6

Terzi E, Kartal S, Pişkin S, Stark, N, Kantürk, and White R. (2018) Colemanite: A fire retardant candidate for wood plastic composites, BioRes. 13(1): 1491-1509.

Tian C, \& Wang, Hai \& Liu, Xiulan \& Ma, Zhiguang \& Guo, Huazhi \& Xu, Jianzhong. (2003). Flame retardant flexible poly(vinyl chloride) compound for cable application. Journal of Applied Polymer Science. 89. 3137 - 3142. 10.1002/app.12507.

Troitzsch JH (1998). Overview of flame retardants: Fire and fire safety, markets and applications, mode of action and main families. Role in fire gases and residues. Chemistry Today 16.

Van der Veen I, de Boer J (2012) Phosphorus flame retardants: Properties, production, environmental occurrence, toxicity and analysis, Chemosphere 88(10):1119-1153. doi.org/10.1016/j.chemosphere.2012.03.067

Wang Q, Li J, Winandy J (2004) Chemical mechanism of flame retardance of boric acid on wood, Wood Sci Technol 38(5):375-389. doi.org/10.1007/s00226-004-0246-4

Wang J, Wang F, Gao Z, Zheng M, Sun J (2016) Flame retardant medium-density fiberboard with expanded vermiculite, Bioresources 11(3)6940-6947. doi:10.15376/biores.11.3.6940-6947

Wu Y, Yao C, Hu Y, Zhu X, Qing Y, Wu Q, (2014) Comparative Performance of Three Magnesium Compounds on Thermal Degradation Behavior of Red Gum Wood, Materials (Basel) 7(2) 637-652. doi:10.3390/ma7020637 


\section{Tables}

Table 1. Characteristics of flame retardant compositions (FRC) as determined in part I of this study

\begin{tabular}{llllll}
\hline $\begin{array}{l}\text { Flame } \\
\text { retardant } \\
\text { composition }\end{array}$ & $\begin{array}{l}\text { Carrier } \\
\text { material }\end{array}$ & $\begin{array}{l}\text { Intraparticle } \\
\text { intruded } \\
\text { volume (for } \\
\text { carrier } \\
\text { material) } \\
\left(0.004-d^{*} \mu \mathrm{m} /\right. \\
\left.\mathrm{cm}^{3} \cdot \mathrm{g}^{-1}\right)\end{array}$ & $\begin{array}{l}\text { Amount of } \\
\text { active } \\
\text { substance } \\
\left(\mathrm{CaCl}_{2}\right) \text { in } \\
\text { carrier }\end{array}$ & $\begin{array}{l}{ }^{1)} \text { Water } \\
\text { content } \\
\text { determined at } \\
103 \pm 2{ }^{\circ} \mathrm{C}\end{array}$ & $\begin{array}{l}{ }^{2} \text { Water } \\
\text { content } \\
\text { determined } \\
\text { at } 200{ }^{\circ} \mathrm{C}\end{array}$ \\
& & & & \\
& & & & \\
\hline FRC1 & $\mathrm{C} 1$ & 0.775 & $26 \%$ (solid) & 33.2 & 34.3 \\
FRC2 & $\mathrm{C} 2$ & 0.501 & $16 \%$ (solid) & 24.2 & 25.3 \\
\hline
\end{tabular}

${ }^{1)}$ determined using halogen moisture determination balance equipment ${ }^{2}$ calculated from the weight loss determined on samples dried at $200^{\circ} \mathrm{C}$ over one hour 
Table 2 Material characteristics of wood composites with flame retardant addition

\begin{tabular}{|l|l|l|}
\hline $\begin{array}{l}\text { Wood composite } \\
\text { samples with FR } \\
\text { addition }\end{array}$ & $\begin{array}{l}\text { Density }\left[\mathrm{kg} \cdot \mathrm{m}^{-3}\right] \\
(\mathrm{CV} \%)\end{array}$ & $\begin{array}{l}\text { Moisture content [\%] } \\
(\mathrm{CV} \%)\end{array}$ \\
\hline Ref. (no FR addition) & $\begin{array}{l}635 \\
(6.0)\end{array}$ & $\begin{array}{l}9.8 \\
(0.5)\end{array}$ \\
\hline NP FRC 10 & 645 & 11.0 \\
& $(3.0)$ & $(0.7)$ \\
\hline GCC 10 & 642 & 9.0 \\
& $(12.0)$ & $(1.4)$ \\
\hline GCC 20 & 643 & 8.5 \\
& $(11.2)$ & $(1.9)$ \\
\hline FRC1 10 & 640 & 10.2 \\
& $(7.8)$ & $(2.1)$ \\
\hline FRC1 20 & 659 & 11.7 \\
& $(12.3)$ & $(0.9)$ \\
\hline FRC2 10 & 648 & 9.4 \\
& $(9.9)$ & $(1.3)$ \\
\hline FRC2 20 & 644 & 9.9 \\
& $(11.3)$ & $(1.6)$ \\
\hline
\end{tabular}


Table 3 Comparison of the parameters determined in cone calorimetry trials

\begin{tabular}{ll|l|l|l}
\hline & FRC1 & $\mathrm{C} 1$ & $\mathrm{CaCl}_{2}$ & Ref \\
\hline Sampling time interval $\Delta \mathrm{t}(\mathrm{s})$ & 1948 & 1948 & 1955 & 1948 \\
\hline Self-extinguishing after (s) & 670 & 749 & $\begin{array}{l}\text { No self- } \\
\text { extinguishing }\end{array}$ & $\begin{array}{l}\text { No self- } \\
\text { extinguishing }\end{array}$ \\
\hline $\begin{array}{l}\text { Heat release rate per unit area } \mathbf{q}_{\mathrm{A}, \max }^{\circ} 133.0 \\
{\left[\mathrm{~kW} / \mathrm{m}^{2}\right]}\end{array}$ & 191.1 & 148.6 & 202.0 \\
$\begin{array}{l}\text { Total heat per unit area released during the } \\
\text { entire test } \mathbf{Q}_{\mathrm{A}, \text { tot }}\left[\mathrm{kW} / \mathrm{m}^{2}\right]\end{array}$ & 113.8 & 121.7 & 127.46 \\
\hline
\end{tabular}




\section{Figure Captions}

Fig. 1 Scanning electron micrograph (SEM) of a) mineral-based carrier (C1); b mineral-based carrier (C2); c) FRC1; d) FRC2

Fig. 2 Pore volumes for carrier 1 (C1) and carrier 2 (C2). The peaks $<1 \mu \mathrm{m}$ represent intraparticle pore volumes and peaks $\geq 1 \mu \mathrm{m}$ represent interparticle pore volumes for $\mathrm{C} 1$ and $\mathrm{C} 2$, respectively.

Fig. 3 Experimental setup used to determine the flame retardant behavior of single layer particle board

Fig. 4 Water absorption capacity for a) mineral carrier material and b) FRC1, FRC2 and $\mathrm{CaCl}_{2}$ at relative humidity $(\mathrm{RH})$ of $65 \%$ and $95 \%$, respectively

Fig. 5 a) Thermograms and b) 1st derivative thermograms (DTG) of FRC1, FRC2 and the mineral carriers $\mathrm{C} 1$ and $\mathrm{C} 2$.

Fig. 6 a) Temperature triggered water release from FRCs exposed to $200^{\circ} \mathrm{C}$ for one hour after acclimatization and b) water re-absorption capacity of FRCs at $65 \%$ relative humidity $(\mathrm{RH})$ following previous exposure at $200^{\circ} \mathrm{C}$ for 1 hour.

Fig. 7 SEM (scanning electron microscopy) images of the cross section of MUF wood composites with $20 \mathrm{wt} . \%$. FRC1 addition

Fig. 8 The effect from $20 \mathrm{wt}$.\% FRC1 addition on temperature development in the core and surface layer of MUF wood composite determined during manufacturing (hot press).

Fig. 9 Internal bond (IB) strength for wood composites with different FRC addition in $\%$ of the reference (i.e. composite without FRC addition)

Fig. 10 The potential of FRC as a flame retardant demonstrated by the selfextinguishing time of MUF boned wood composites following prior flame exposure

Fig. 11 a) heat release rate (HRR); b) total heat release rate (THR); c) smoke production rate (SPR) and d) total smoke production (TSP) determined on threelayer particle board with 20wt.\% FRC addition in outer layer in comparison to reference (without any addition) and particle boards with addition of individual components of the carrier i.e. inorganic carrier material (C1) and $\mathrm{CaCl}_{2}$ (amount normalized to the amount for the variant with the FRC), respectively. 
Fig. 12 Concentration of hydrogen chloride $(\mathrm{HCl})$ in flue gas determined on threelayer particle board with 20wt.\% FRC addition in outer layer in comparison to reference (without any addition) and particle boards with addition of individual components of the carrier i.e. inorganic carrier material $(\mathrm{C} 1)$ and $\mathrm{CaCl}_{2}$ (amount normalized to the amount for the variant with the FRC), respectively. 

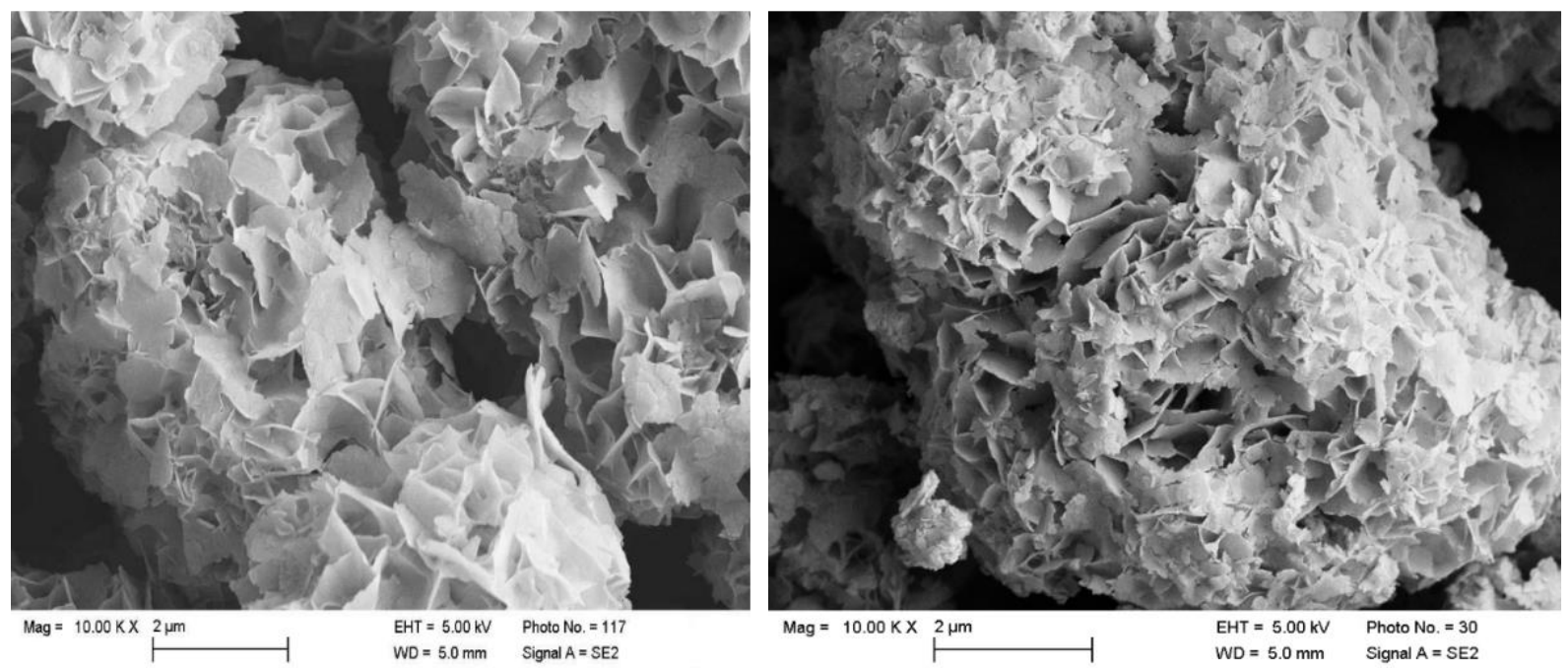

a)

b)
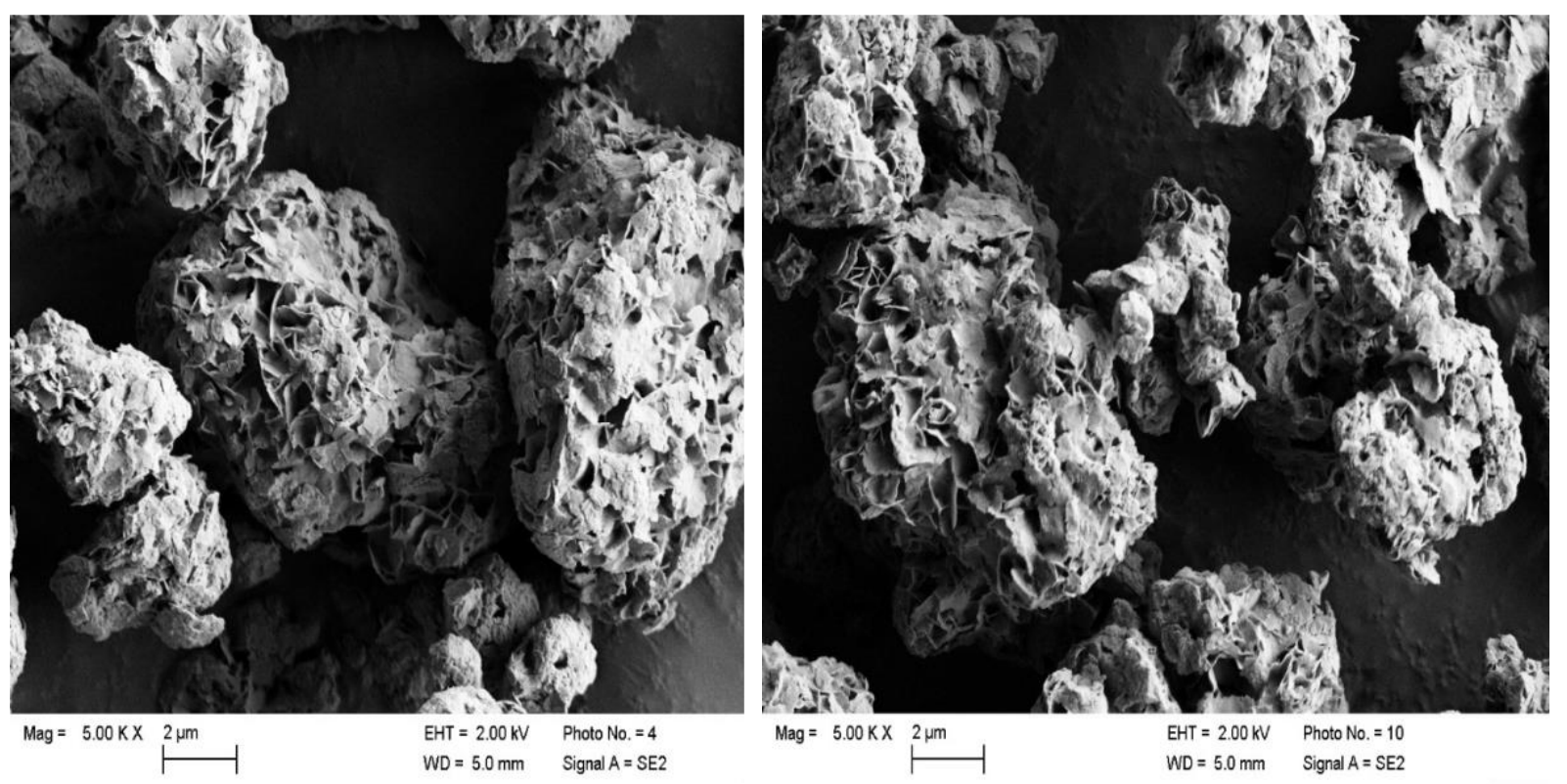

c)

d)

Fig. 1 


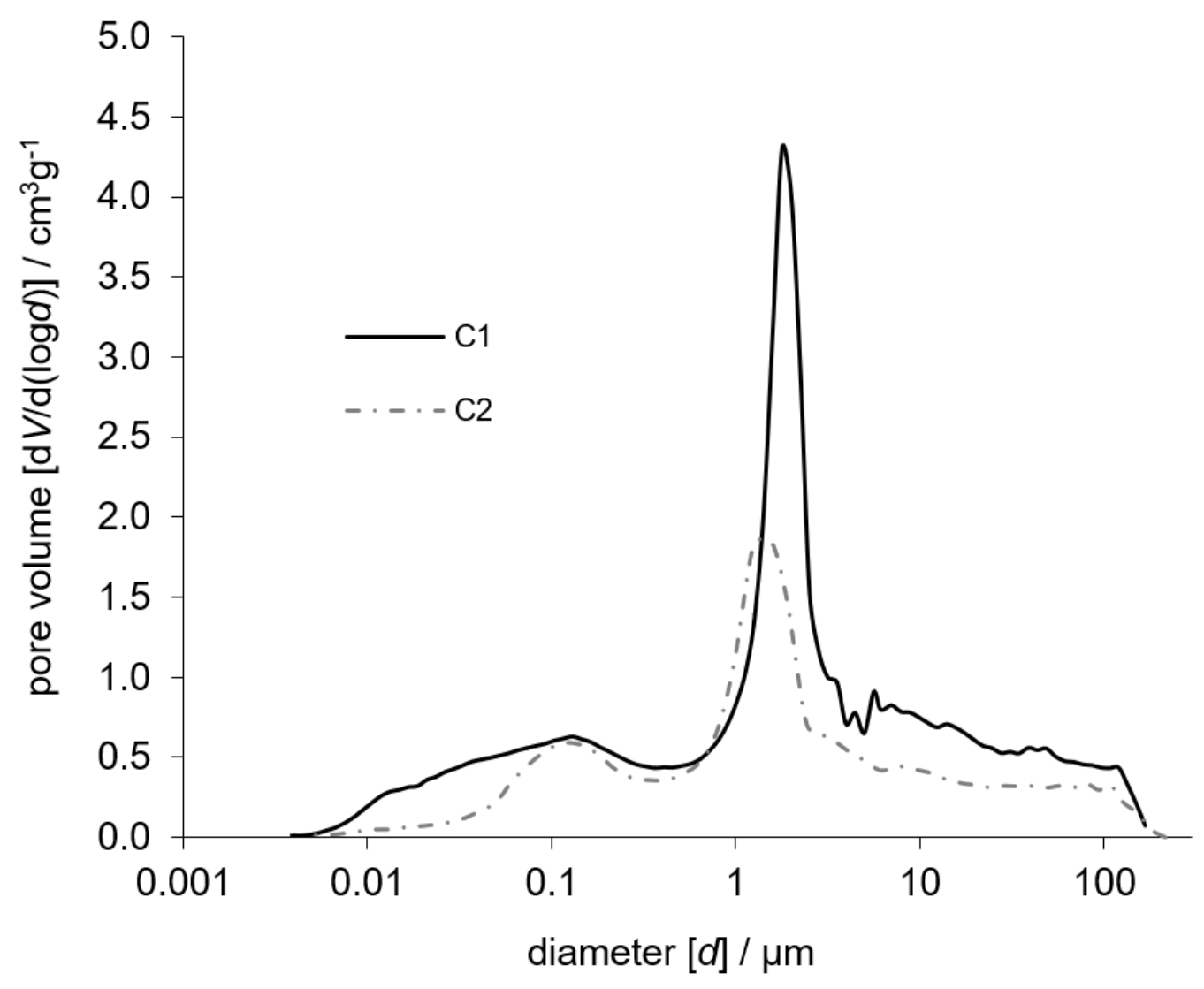

Figure 2 


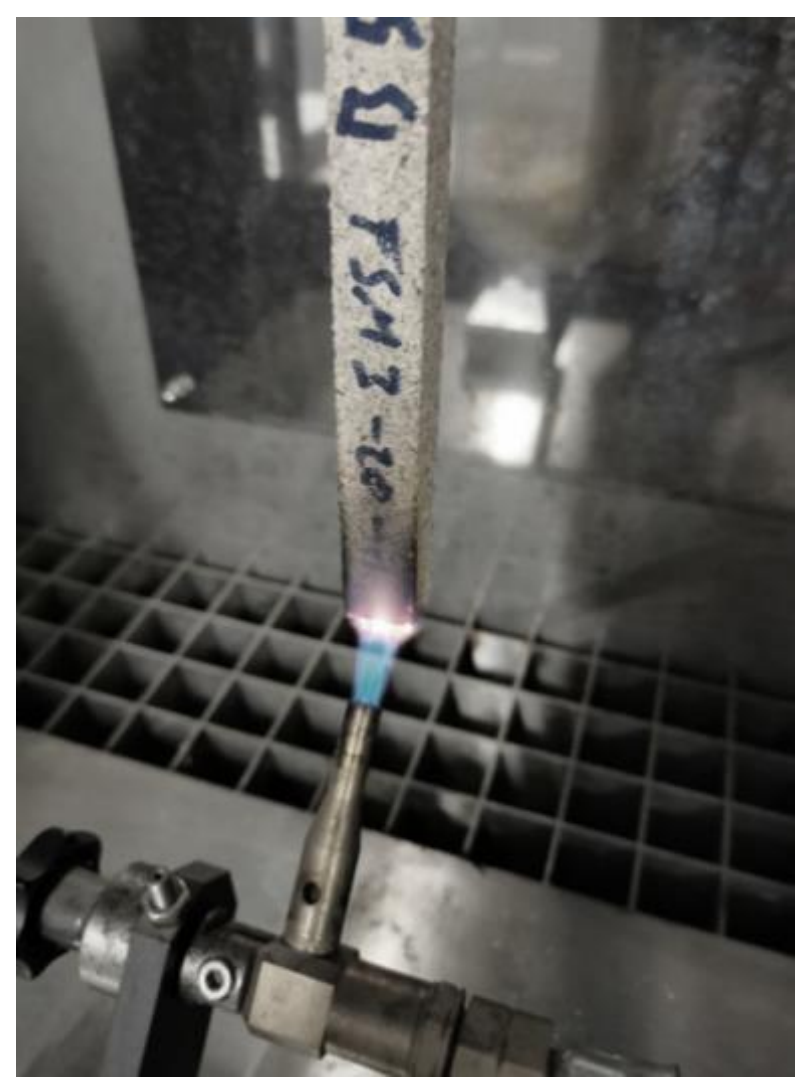

Fig. 3 


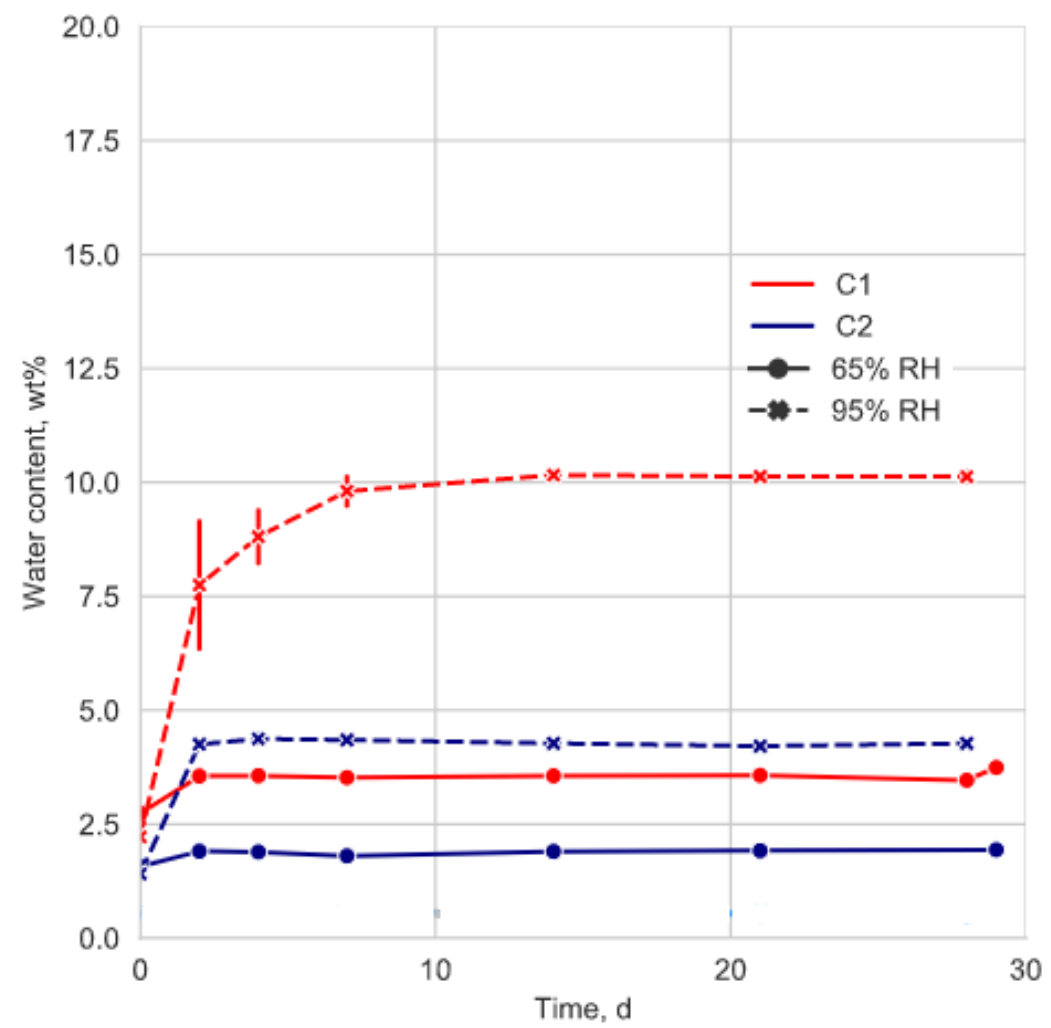

a)

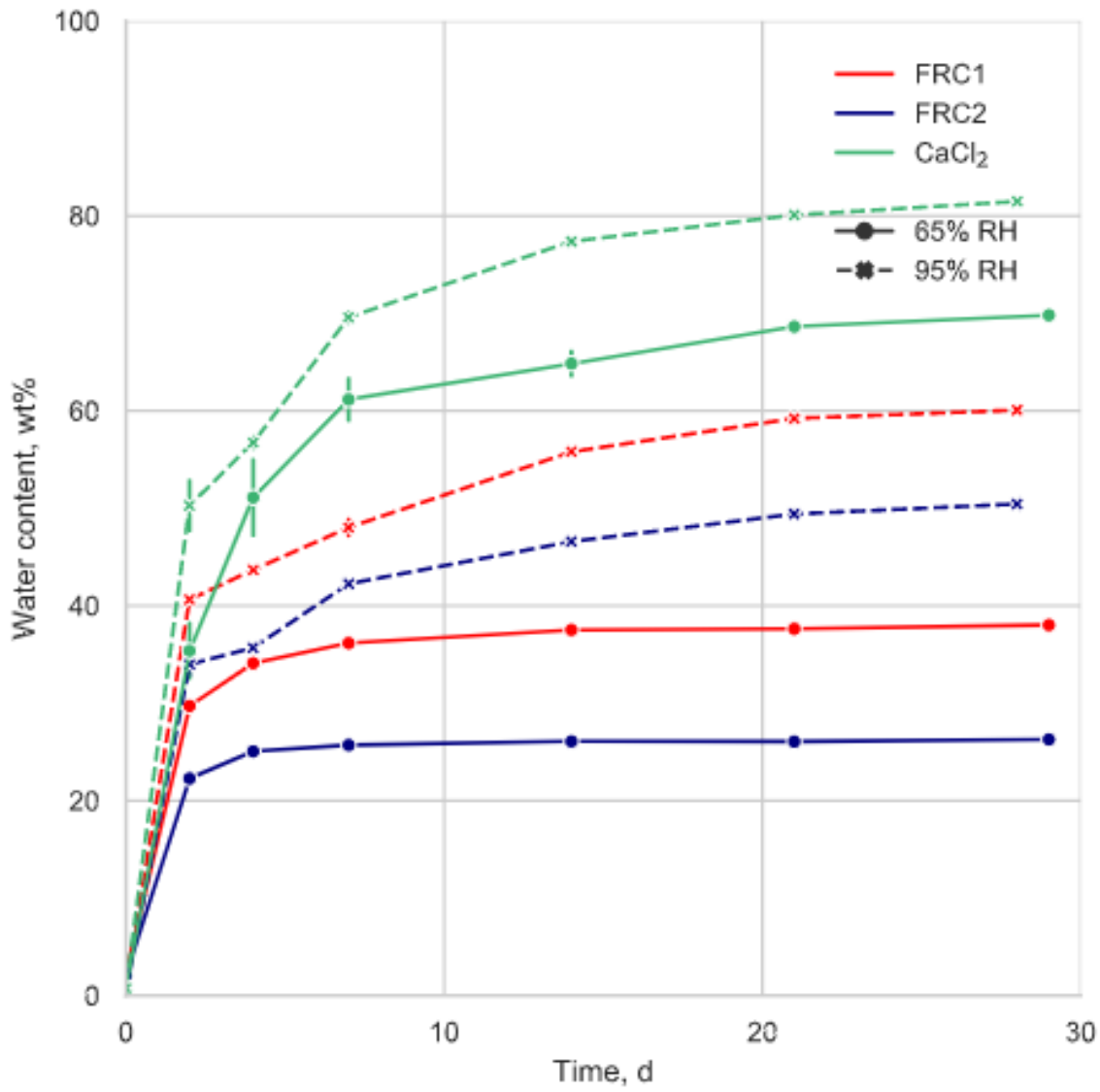

b)

Fig. 4 


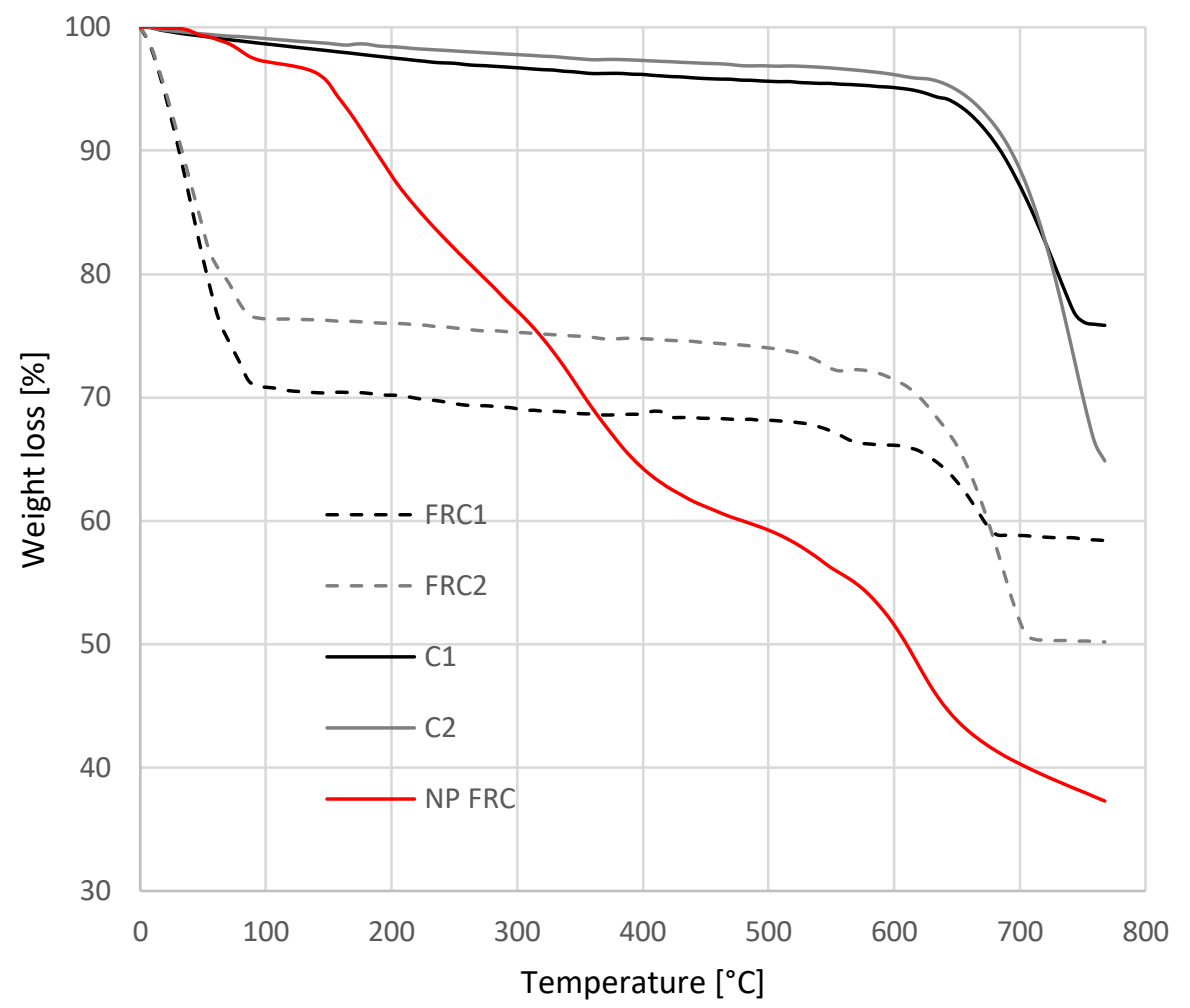

a)

Temperature $\left[{ }^{\circ} \mathrm{C}\right]$

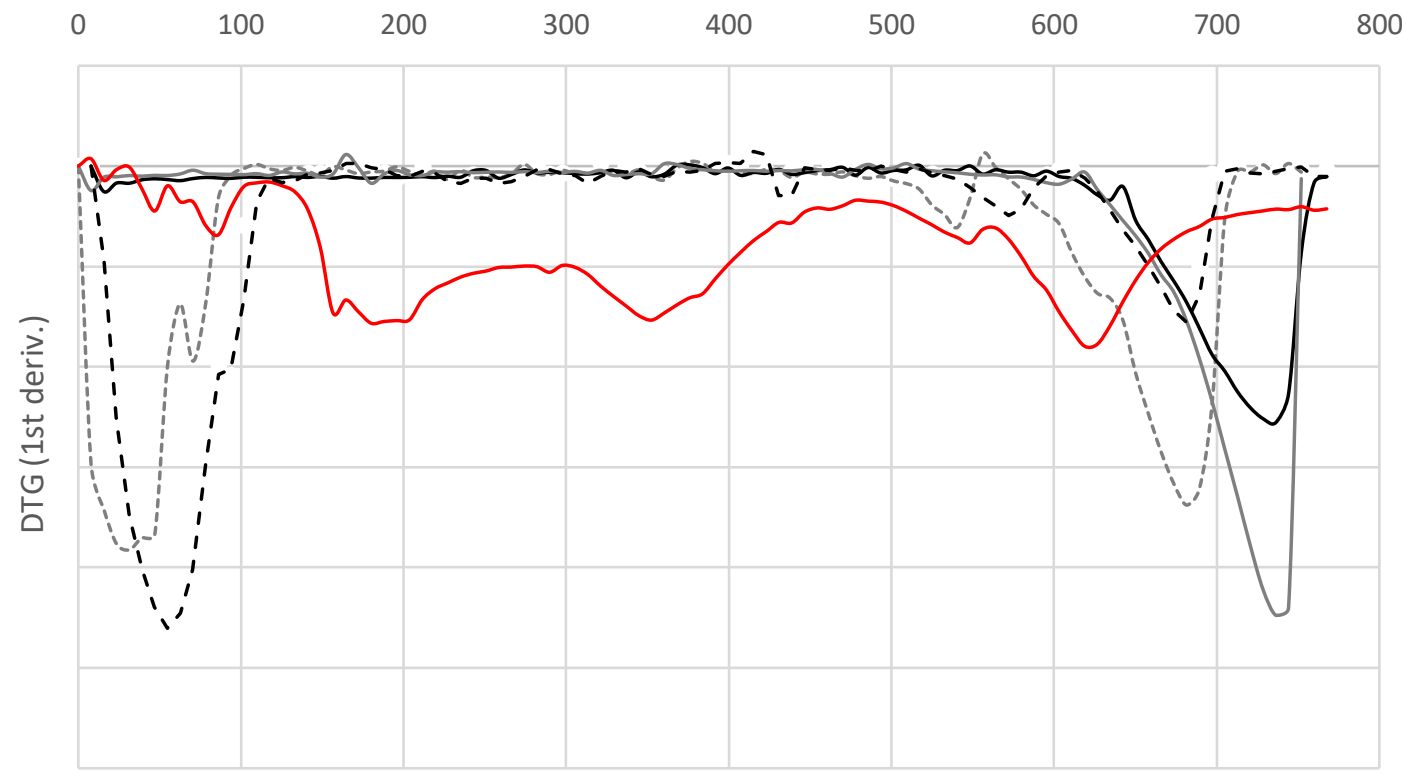

b)

Fig. 5 


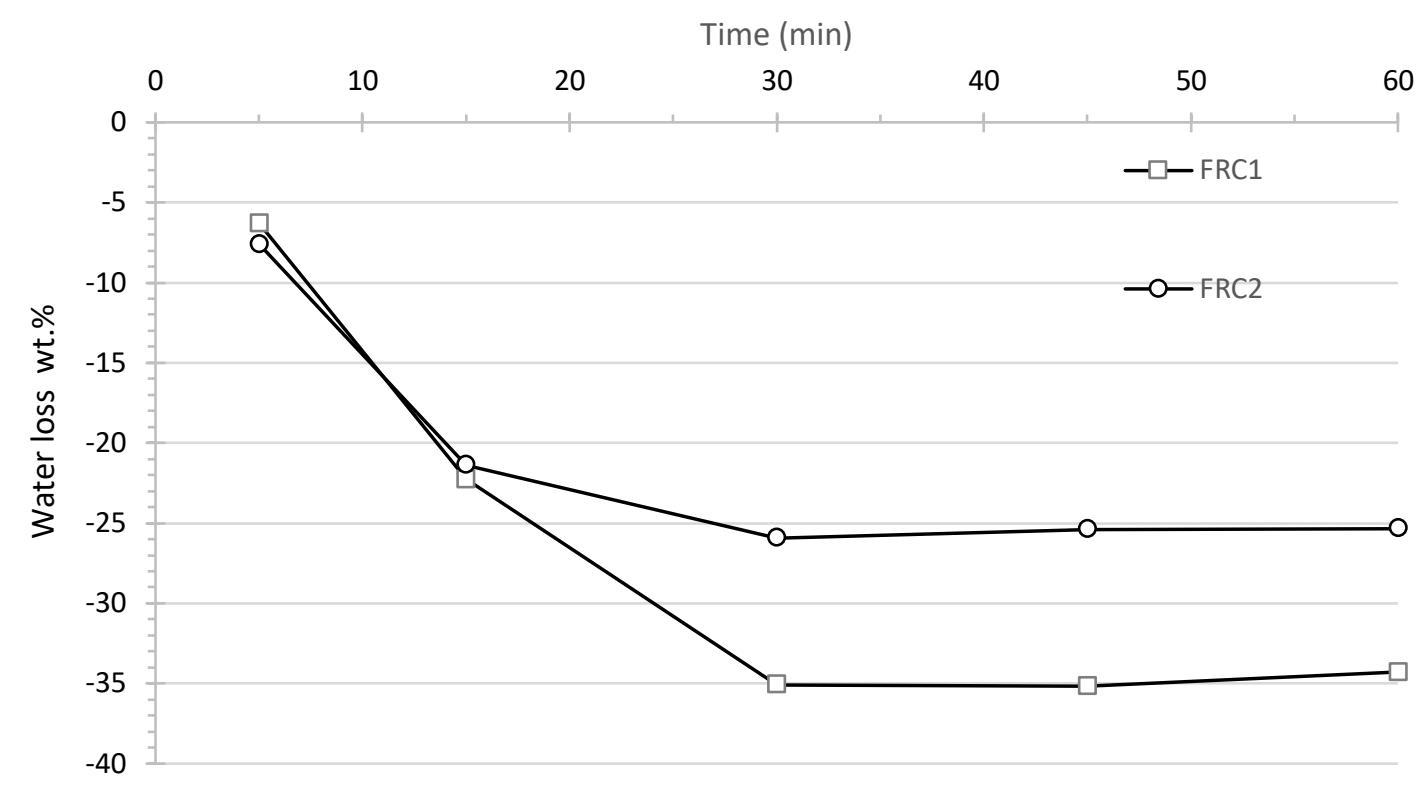

a)

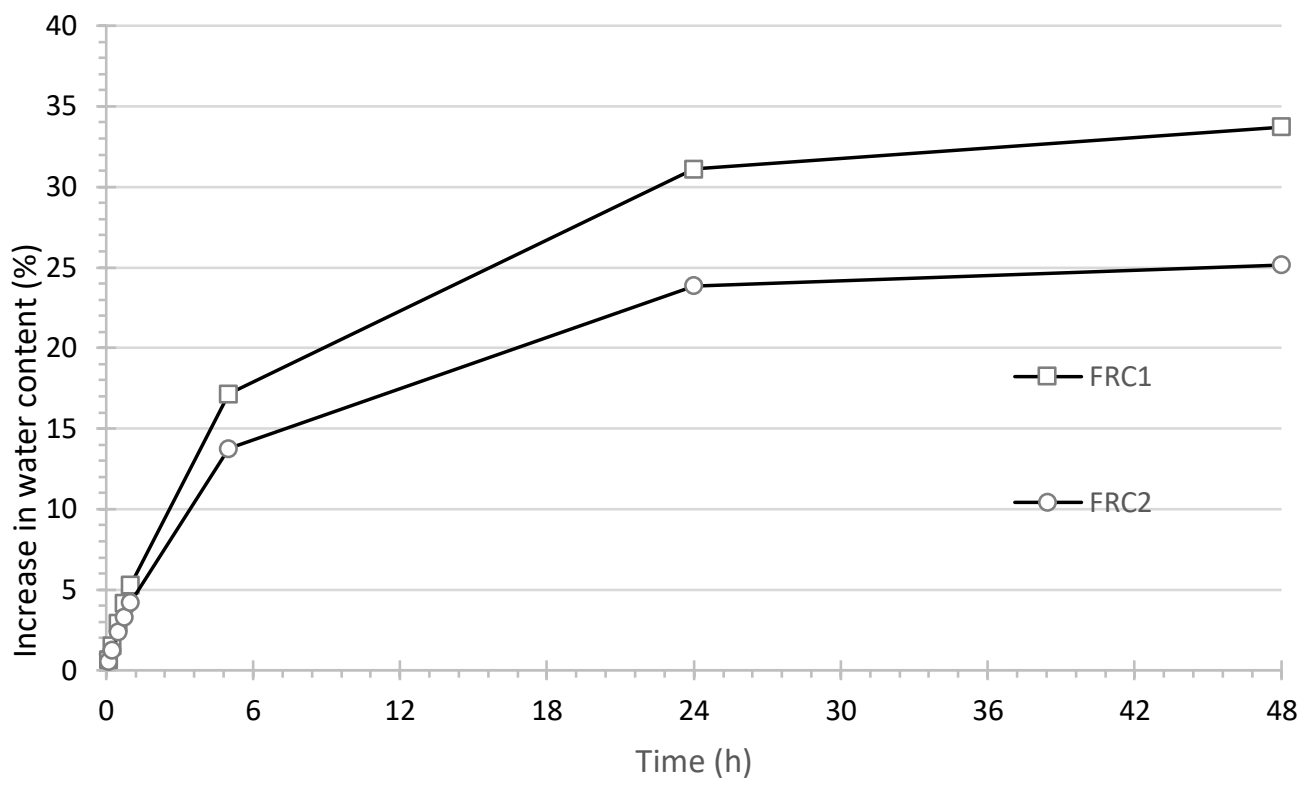

b)

Fig.6 


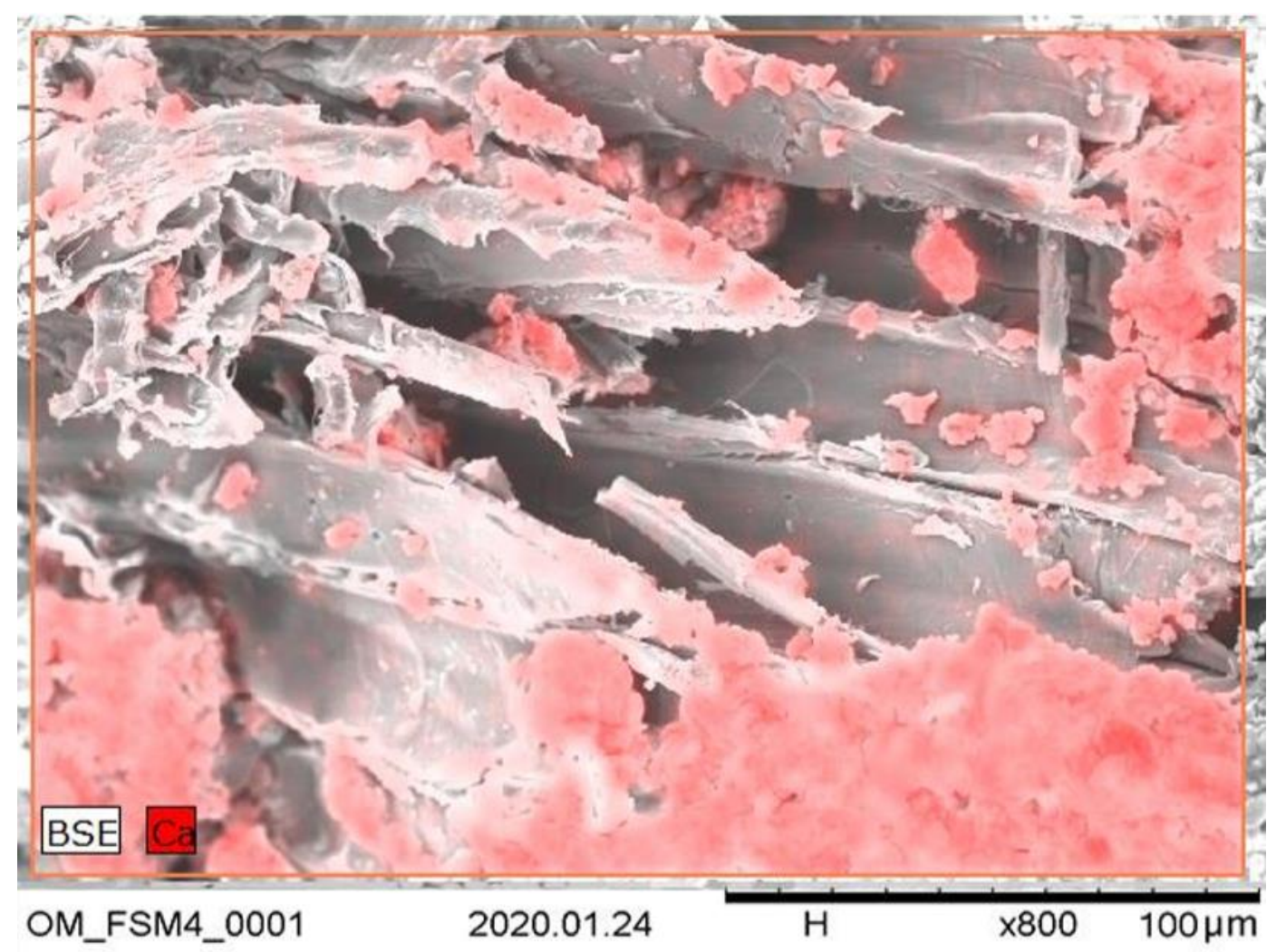

Fig. 7 


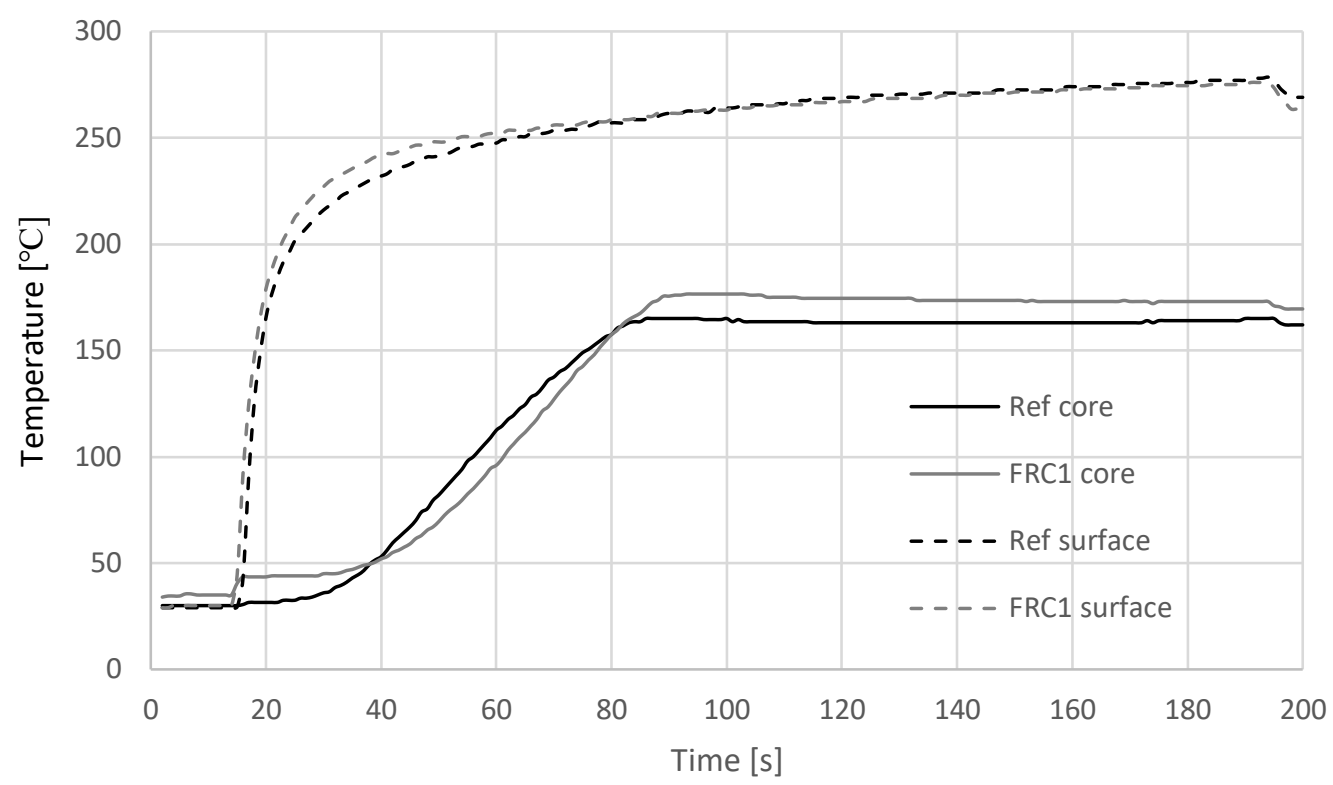

Fig. 8 


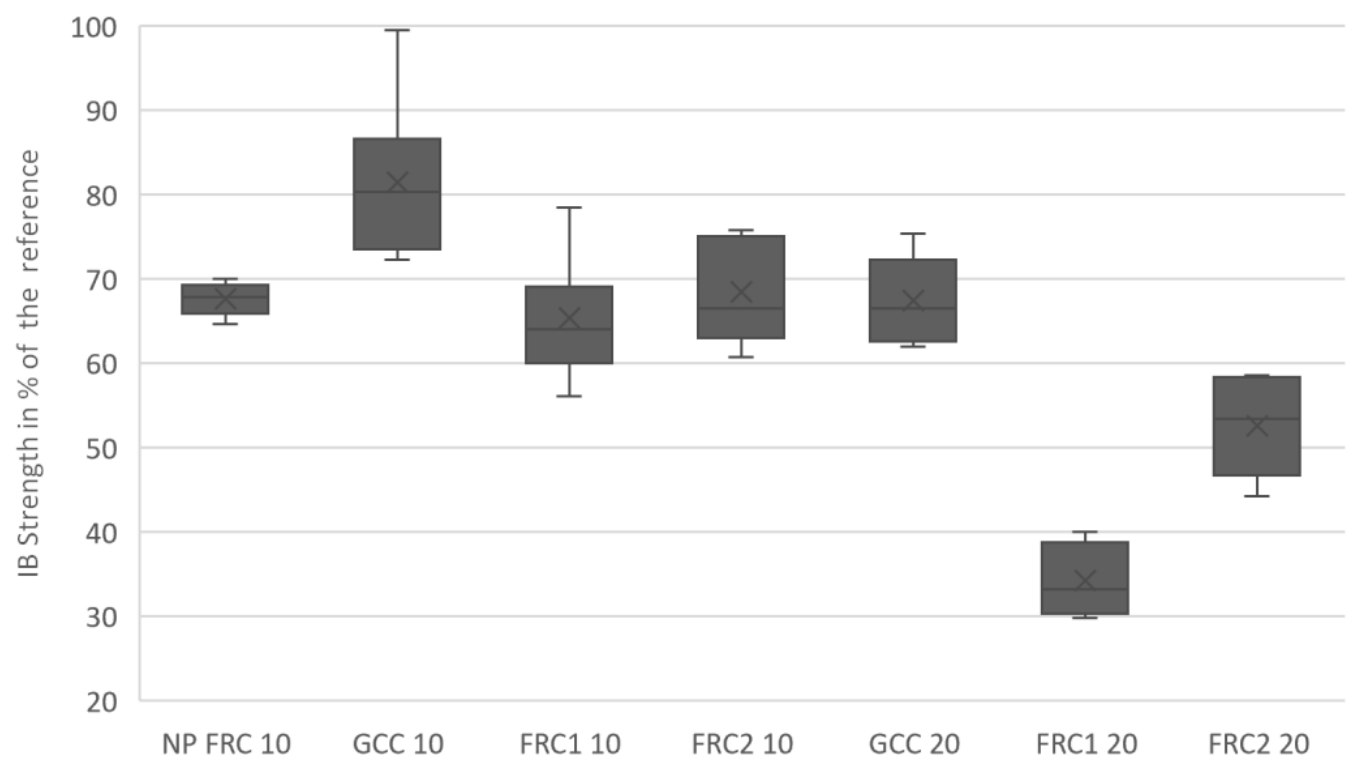

Fig. 9 


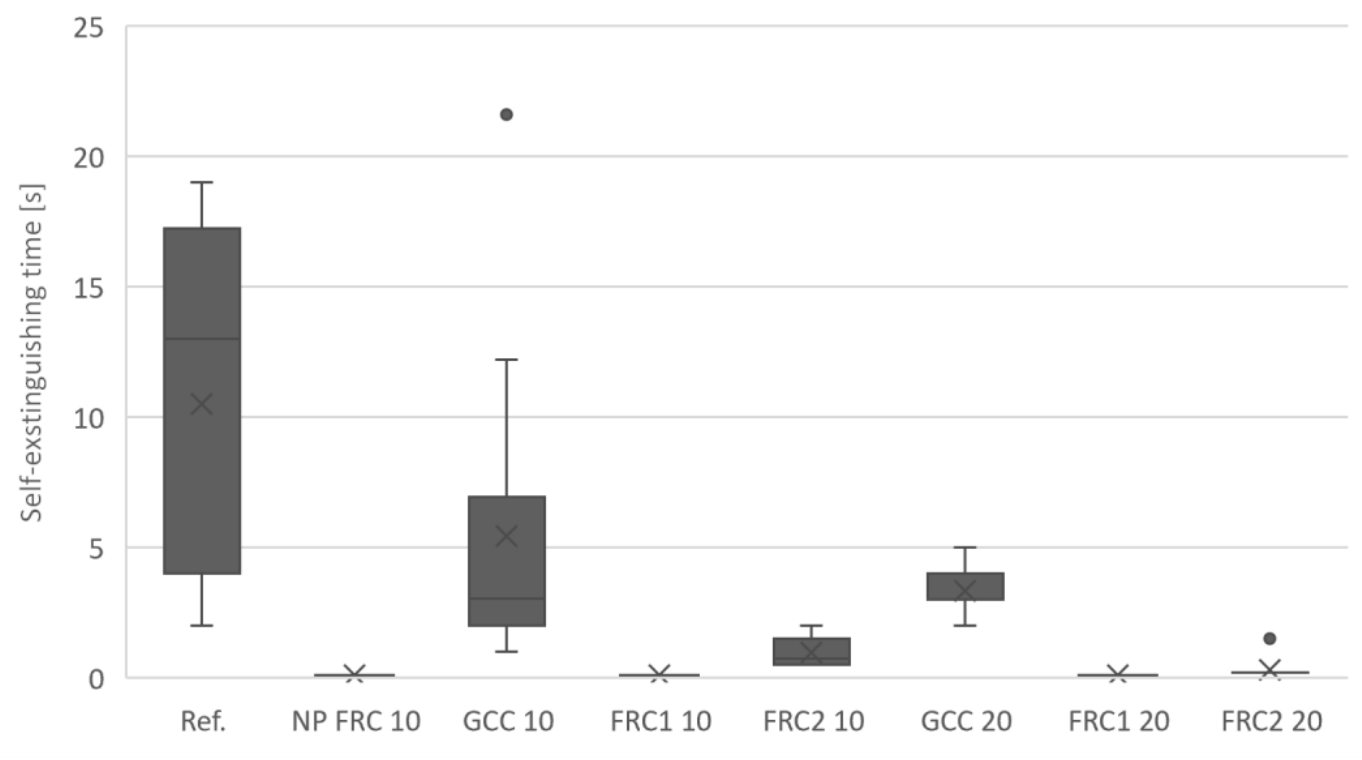

Fig. 10 

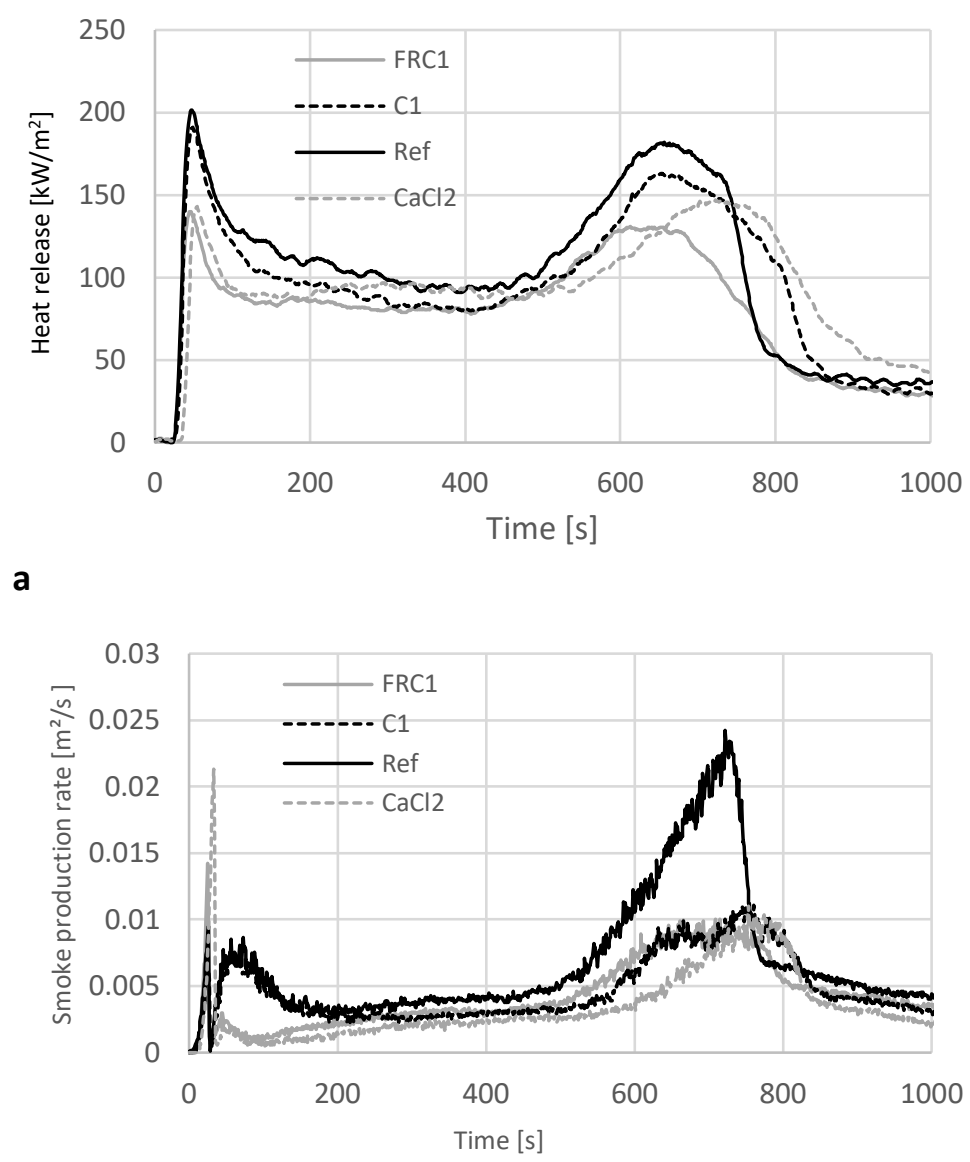

c)

Fig. 11

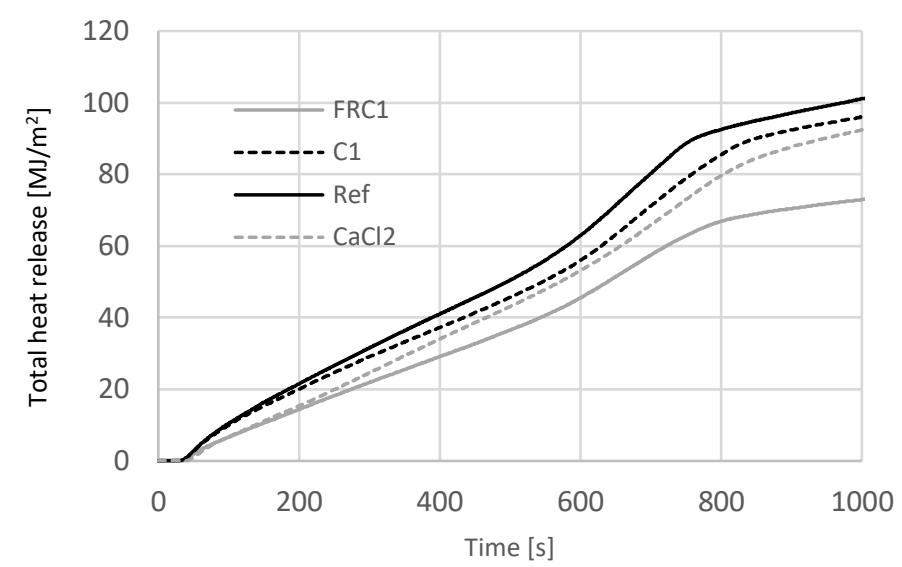

b

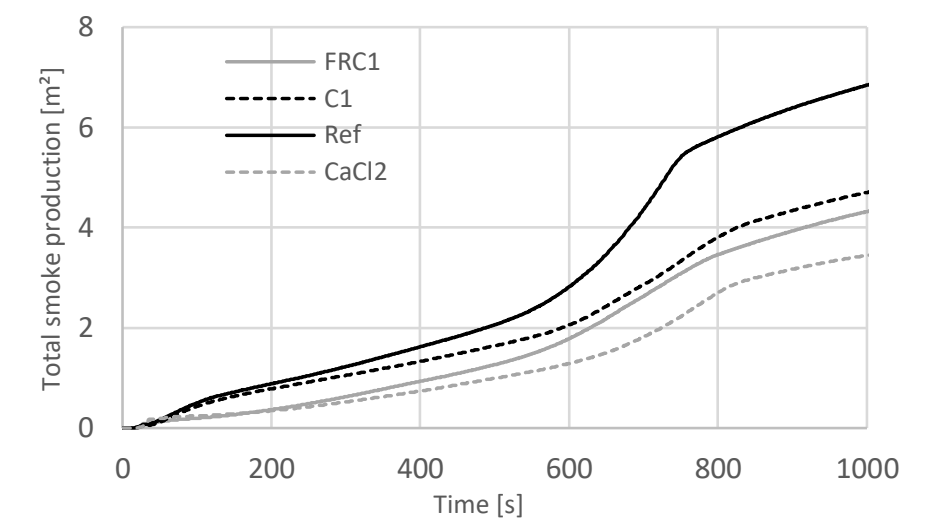

d) 


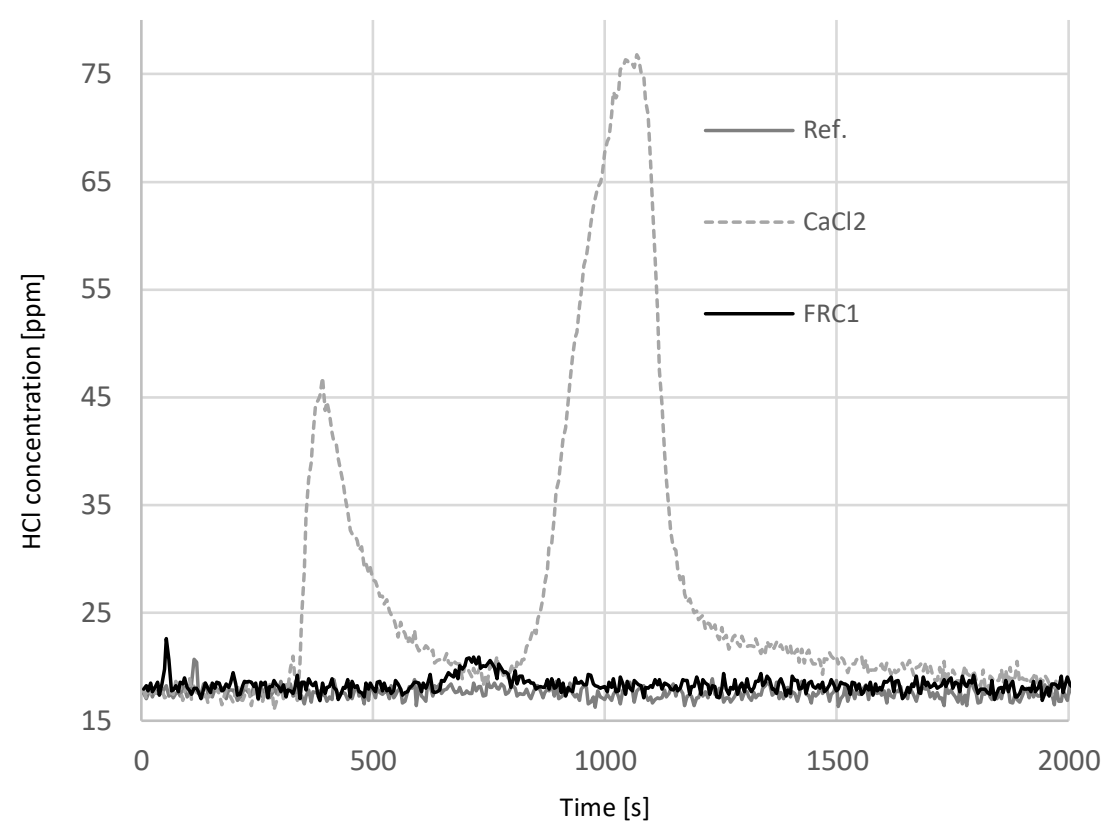

Fig. 12 